\title{
Circulation and Nutrients in Middepth Atlantic Waters
}

\author{
Mitsuhiro KaWASE ${ }^{1}$ and Jorge L. Sarmiento \\ Geophysical Fluid Dynamics Program, Princeton University, New Jersey
}

\begin{abstract}
Isopycnal analyses of distributions of salinity, oxygen, apparent oxygen utilization, nitrate, and silica in the depth range $800-3000 \mathrm{~m}$ in the North and Tropical Atlantic Ocean are carried out using data from the Transient Tracers in the Oceans, Meteor cruise $56 \mathrm{leg} 5$, Atlantis II cruise 109 legs 1 and 3, and the GEOSECS Atlantic Study. The results are summarized in isopycnal distribution maps and propertyproperty plots. The layer between 800 and $1500 \mathrm{~m}$ is oxygen poor and nutrient rich and is poorly ventilated. Below this is a better aerated layer with the deep western boundary current, part of which separates along the equator. Regeneration of nutrients and consumption of oxygen persist into the deep ocean in regions off the west coast of Africa. The Mediterranean Outflow Water apparently is causing significant cross-isopycnal mixing through salt fingering. The resultant cross-isopycnal velocity may be large enough to cause significant vorticity stretching.
\end{abstract}

\section{INTRODUCTION}

Reid [1981] has stated that the middepth ocean is a region "for which we have very little information and very vague concepts." Indeed, since the pioneering work by Wust [1935], our knowledge of the Atlantic Ocean circulation between 1000 $\mathrm{m}$ and the abyssal ocean has not progressed at the same pace as that of shallower surfaces, although since the early 1970's there has been an increasing number of studies devoted to circulation at these depths, notably by Reid himself [Reid and Lynn, 1971; Reid, 1978, 1979, 1981].

This paper is a continuation of our effort to report the nutrient patterns seen in the North and Tropical Atlantic Ocean in the Transient Tracers in the Ocean (TTO) project and other recent data sets. In this study, we start from the depth of the Antarctic Intermediate Water and cover the depth range between this level and the crest of the MidAtlantic Ridge at about $3000 \mathrm{~m}$. As in the earlier paper in this series [Kawase and Sarmiento, 1985], our strategy is to use isopycnal analysis. Spatial distribution maps of nutrients on potential density surfaces are produced using an objective mapping method [Sarmiento et al., 1982b], and plots of nutrient against salinity are employed to identify source water characteristics and the presence of nonconservative/crossisopycnal processes. The quantities to be investigated are salintiy, oxygen, apparent oxygen utilization (AOU), silica, and nitrate.

The picture of the deep Atlantic above the crest of the Mid-Atlantic Ridge that emerges from the nutrient data divides the depth range under our investigation into two broad strata. The shallower stratum of the two is the layer below the "ventilated thermocline" [Luyten et al., 1983; Sarmiento et al., 1982a; Kawase and Sarmiento, 1985] down to about $1300 \mathrm{~m}$, where ventilation appears extremely poor. (By "ventilation," we mean propagation of water mass characteristics such as potential vorticity and oxygen concentration away from the ocean surface into the interior due to advection and/or mixing.) Below this is the North Atlantic Deep Water stratum

\footnotetext{
${ }^{1}$ Now at Department of Earth, Atmospheric and Planetary Sciences, Massachusetts Institute of Technology, Cambridge.

Copyright 1986 by the American Geophysical Union.

Paper number $6 \mathrm{C} 0256$.

0158-0227/86/006C-0256\$05.00
}

that features the deep western boundary currents, which carry newly formed deep waters from their source region, and which consequently is better ventilated than the layer above.

The Mediterranean Outflow Water tongue, with its highsalinity value, appears to be driving active salt fingering over a wide area in the subtropical North Atlantic. Possible consequences of this on the nutrient distribution and circulation in this depth range will be discussed. In particular, we will argue that the Mediterranean Undercurrent of Ivers [1975] may be driven by vorticity stretching due to the cross-isopycnal velocity associated with salt fingering.

The minimum in oxygen/maximum in nutrients off West Africa that has been observed at shallower depths [Kawase and Sarmiento, 1985] is seen to persist down to depths of 3000 $\mathrm{m}$ or more. Speculations on possible mechanisms for the maintenance of this feature will be discussed.

One remarkable feature of the circulation in the lower stratum is the separation of the deep western boundary current from the coast at the equator. Possible dynamical mechanisms for this separation will be discussed.

\section{DATA}

As in Kawase and Sarmiento [1985], our data set consists of measurements from the TTO North and Tropical Atlantic Studies (TTO-NAS and TTO-TAS, respectively), Meteor cruise 56 leg 5 (R. Schlitzer et al., unpublished manuscript, 1986), Atlantis II cruise 109 legs 1 and 3 [Roemmich and Wunsch, 1985], and the GEOSECS Atlantic Study. The cruise tracks for these expeditions are shown in Figures 1 and 2. Once again we observe no significant systematic differences between the GEOSECS and the more recent data sets, although Swift [1984] and Broecker [1985] have reported changes in the water mass characteristics of deep waters south of Greenland. Most of these changes took place at depths greater than those covered in this study. Potential density was calculated using the UNESCO equation of state for seawater [UNESCO, 1981] together with Fofonoffs [1977] algorithm for calculating potential temperature and Bryden's [1973] polynomial for adiabatic temperature gradient. The AOU of a water parcel was defined as the difference between the saturation oxygen level for the potential temperature and salinity of the water parcel and the observed oxygen level. Assuming that the water parcel is saturated with oxygen at the sea surface, AOU should be zero at the sea surface. As the water parcel leaves the sea surface and spends time in the interior of 


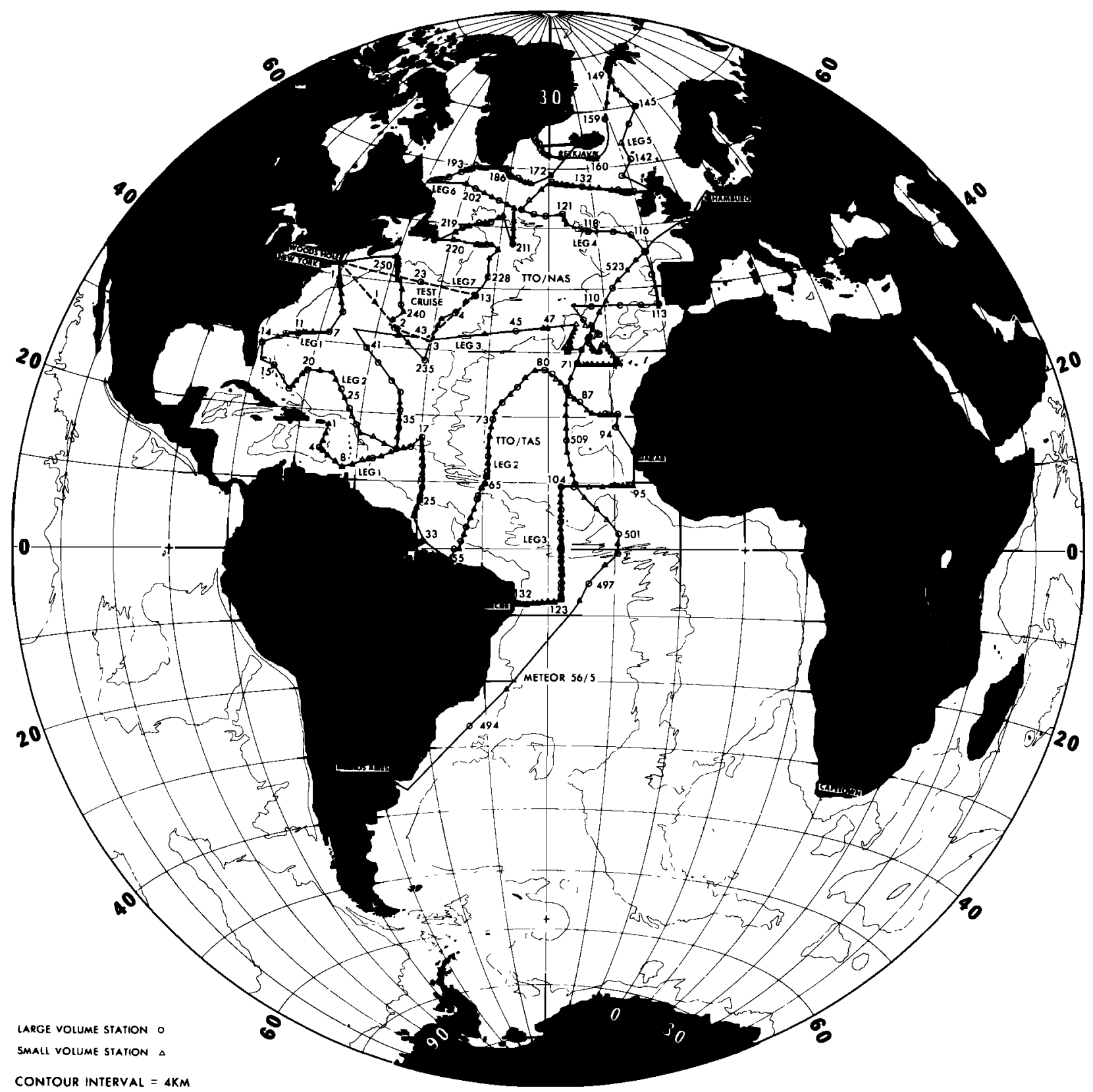

Fig. 1. Cruise tracks for TTO-NAS, TTO-TAS, Meteor cruise $56 \mathrm{leg} 5$, and Atlantis $I I$ cruise 109 legs 1 and 3.

the ocean, its oxygen will be gradually consumed by the bacteria decomposing the organic debris falling from the surface ocean. Hence AOU will increase along with the concentration of the regenerated nutrients.

\section{Potential Density Surfaces}

We select $\sigma_{2}$ as the appropriate potential density to use for the depth range covered by this study (approximately 800 to $3000 \mathrm{~m}$ ). Deeper surfaces in this study do not directly "outcrop" in the region of our study (south of $68^{\circ} \mathrm{N}$ ), and they maintain their depth roughly constant for much of the ocean. Our choice of potential density surfaces follows a "Wustian" guideline: each surface is loosely identified with a particular interior water type, usually a tracer extremum. It does not follow the extremum exactly as Wust's "core layer" does, since a tracer extremum can and does leave the potential density surface with which it is initially identified. We also tried to avoid a large gap in vertical spacing resulting simply because there were no tracer extrema in that depth range. We desired a vertical resolution of about $500 \mathrm{~m}$, which is adequate for the intermediate depth range away from the thermocline and the bottom waters, and chose a potential density surface when necessitated by this criterion.

All the surfaces studied here make contact with the atmosphere to the north of the zero wind stress curl line in the region of Ekman pumping. Some of the potential density surfaces that are used in this study shallow drastically in the northern North Atlantic. It must be noted that, in such a region of steep slope of potential density surfaces, a surface of constant potential density referred to a single reference pressure is not a good representation of the actual surface along which maximum mixing occurs [Reid and Lynn, 1971]. 


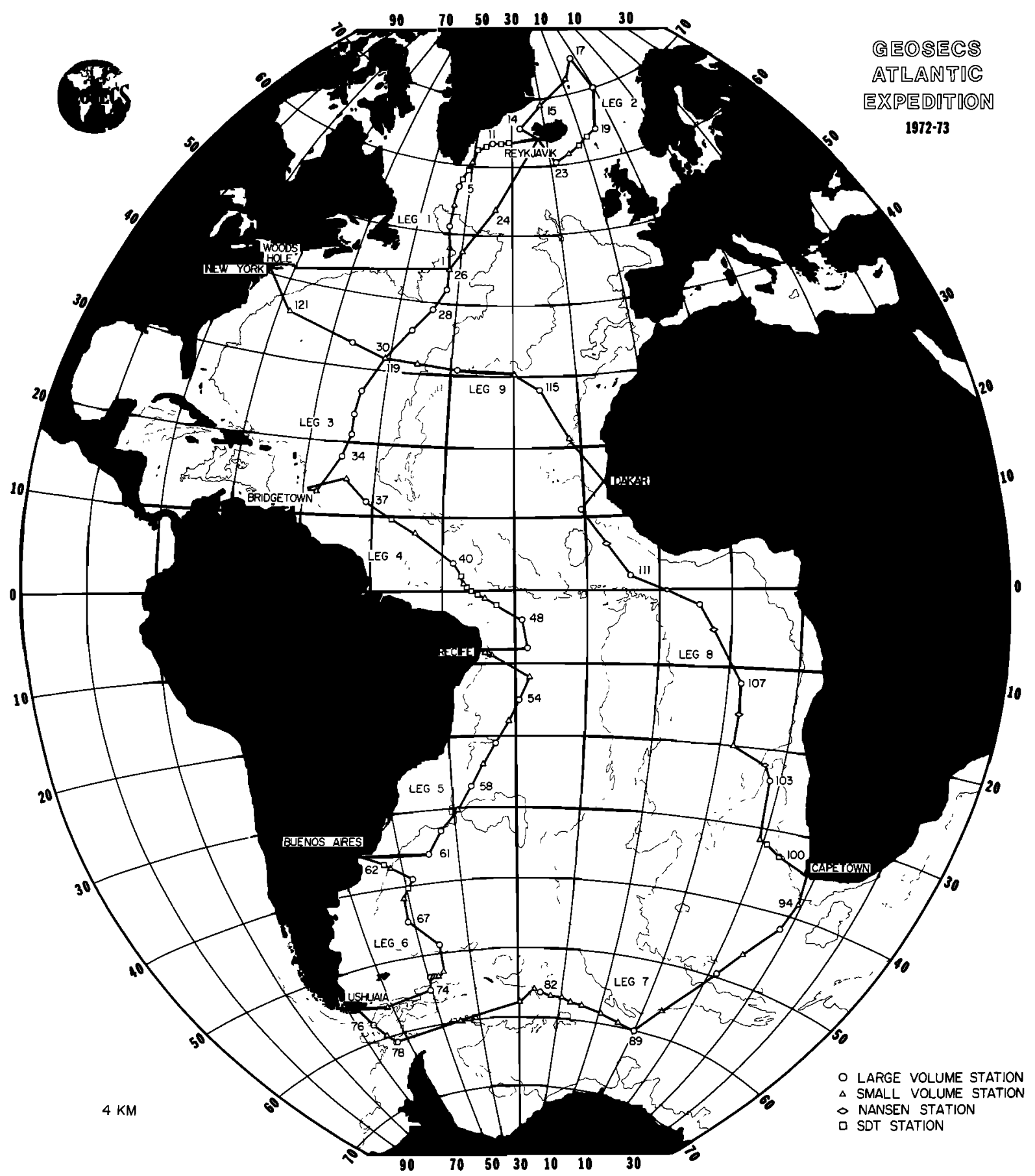

Fig. 2. Cruise tracks for GEOSECS Atlantic Study.

Ideally, isopycnal analyses should be conducted along the "neutral surface," which is everywhere normal to the gradient of (locally defined) potential density. However, determination of neutral surfaces has potential difficulties with nonuniqueness in a multiply connected region [Ivers, 1975]. Such a situation can occur around the Azores Plateau, for example. For the sake of simplicity and unambiguity, we used potential density surfaces with a reference pressure of $2000 \mathrm{dbar}$.

Figures 3 and 4 show two sections of the Atlantic, with $\sigma_{2}$ as the vertical coordinate. Figure 3 shows a north-south section along the GEOSECS western track, and Figure 4 shows an east-west section along the $36^{\circ} \mathrm{N}$ latitude circle of Atlantic II cruise 109 [Roemmich and Wunsch, 1985]. These sections show the tracer extrema that were used for selecting the surfaces to be investigated. Figure 5 shows the outline of the $\sigma_{2}=37.05$ surface with geographical markings. These surfaces are summarized in Table 1. Figure 6 shows the depths of the selected surfaces.

The shallowest surface in the present study, $\sigma_{2}=36.4$, lies within the Antarctic Intermediate Water, which can be seen as a tongue of low-salinity water from the south in the GEOSECS section (Figure 3). This surface lies at a depth of 800 

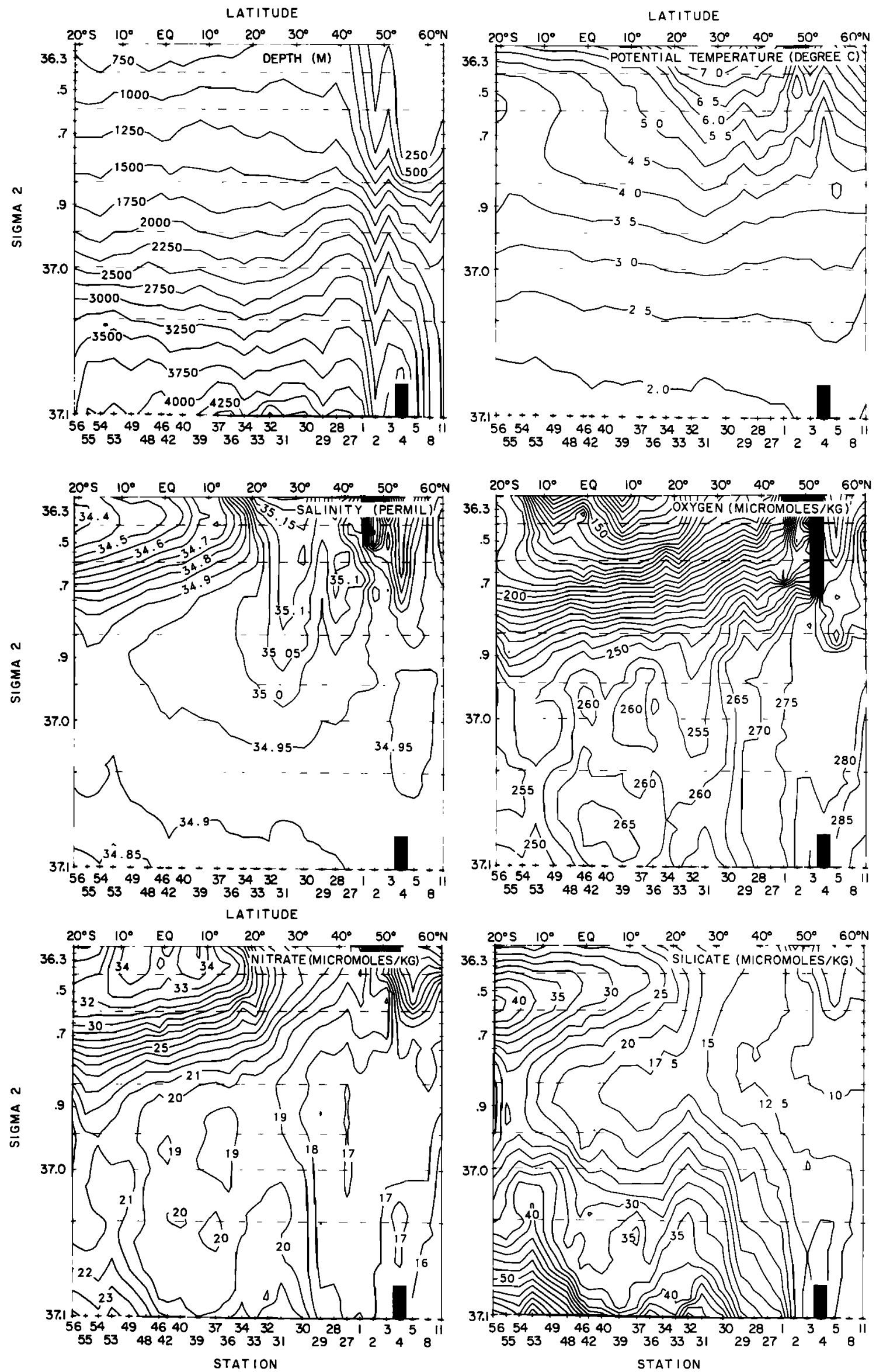

Fig. 3. Sections along the GEOSECS western section. 

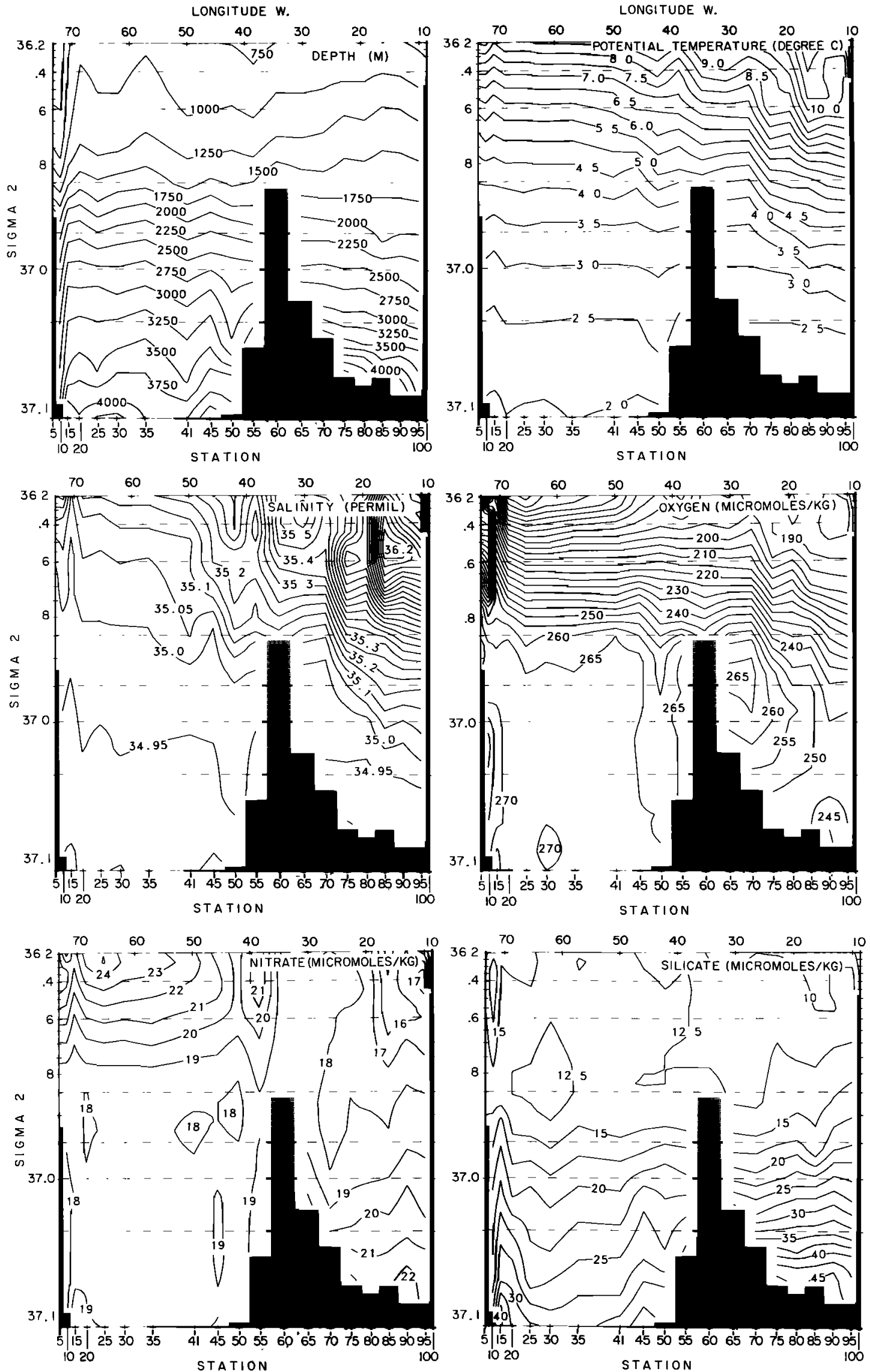

Fig. 4. Sections along the Atlantis II cruise 109 leg 1. 


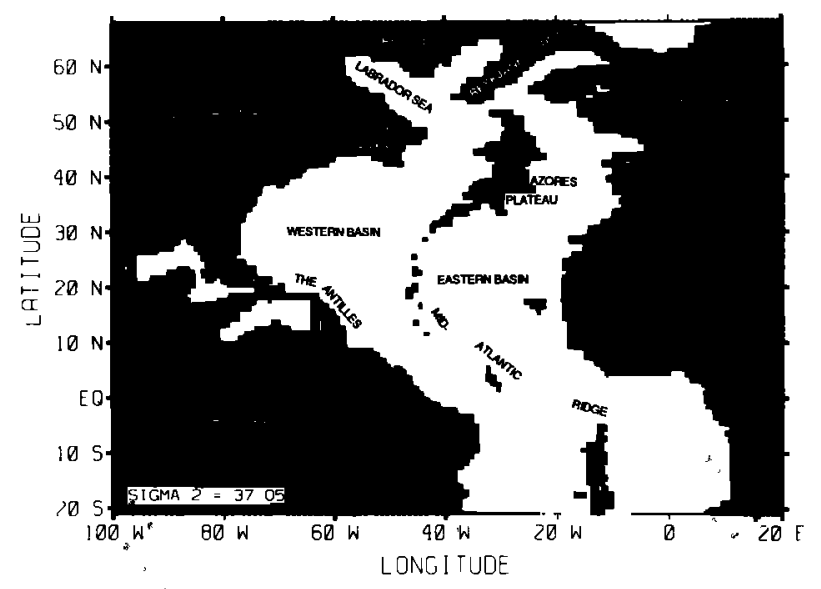

Fig. 5. Outline of the $\sigma_{2}=37.05$ surface with geographical markings.

$900 \mathrm{~m}$ for the most part in the North Atlantic, except in the Gulf Stream recirculation gyre, where it reaches $1100 \mathrm{~m}$. It shallows steeply to the north of $40^{\circ} \mathrm{N}$ and outcrops in the Labrador, Greenland, and Norwegian seas, but it remains deep in the region adjacent to the European coast.

The next surface down is $\sigma_{2}=36.6$. It lies within the highly saline Mediterranean Outflow Water tongue, as can be seen in the Atlantis II salinity section (Figure 4), at a depth of about $1100 \mathrm{~m}$. The overall surface topography is similar to the surface above. We also note that this surface lies within the silicate maximum in the South Atlantic, sometimes called the Circumpolar Intermediate Water. This surface also outcrops to the north.

The next surface is $\sigma_{2}=36.85$. The GEOSECS silica section (Figure 3) shows that this surface lies within the silica minimum in the North Atlantic. We shall refer to this silica minimum water as the Upper North Atlantic Deep Water. The GEOSECS salinity section (Figure 3) shows a region of high salinity descending from the top of the section between stations 36 and 1, and starts spreading out at around this surface. As it extends southward, the core of high-salinity water descends somewhat to about $\sigma_{2}=36.9$. In Wust's [1935] nomenclature, the Upper North Atlantic Deep Water was identified with the intermediate depth salinity maximum throughout the Atlantic. Hence Wust's Upper North Atlantic Deep Water rises above this surface and merges with the Mediterranean Outflow Water $\left(\sigma_{2}=36.6\right)$ in the eastern basin. In the western basin the Mediterranean Outflow Water mixes with the fresher, colder Labrador Sea water, whose source potential density is about 36.875 in terms of $\sigma_{2}$, and gives rise to the Upper North Atlantic Deep Water, as we call it [Talley and McCartney, 1982]. In the interior ocean it lies between 1500- and $1600-m$ depth. This surface outcrops in a small region in the central Labrador Sea and in the Greenland and Norwegian seas but does not outcrop in the main body of the Atlantic south of Iceland.

The next three surfaces, $\sigma_{2}=36.95,37.0$, and 37.05 , lie inside the North Atlantic Deep Water as conventionally identified as the oxygen-rich water that originates in the northern North Atlantic. Wust [1935] has remarked that there seem to be two cores of North Atlantic Deep Water as defined by oxygen maxima, one at about $2500 \mathrm{~m}$ and the other at about $3700 \mathrm{~m}$, and he christened them the Middle and the Lower North Atlantic Deep Waters, respectively. This can be seen in the GEOSECS section (Figure 3). The two shallower surfaces, $\sigma_{2}=36.95$ and 37.0 , lie within the shallower core, and $\sigma_{2}=$ 37.05 lies between the two cores. Edmond and Anderson [1971] have called this weak minimum in oxygen between the two cores the Middle North Atlantic Deep Water. We shall stick to the Wustian terminology and will refer to the shallower core as the Middle North Atlantic Deep Water. None of these surfaces outcrop within the Labrador Sea or south of Iceland.

The Lower North Atlantic Deep Water, which forms the deeper high-oxygen core, lies below the depth range of our concern here. The nutrient characteristics of this and other waters that lie in the Atlantic abyssal basins will be reported in a subsequent paper.

In producing the tracer maps, we changed our autocorrelation function in the mapping scheme from one with a greater zonal extent than was used in the previous study [Sarmiento et al., 1982b] to an isotropic one with the radius of influence equal to the mean of the lengths of the major and minor axes of the former function. This change was made because the assumption that the features in a tracer field have greater zonal than meridional coherence seems no longer tenable in the deep ocean. In particular, there is a danger that major features with possibly greater meridional coherence such as the deep western boundary current may become distorted if we use an anisotropic influence function. The position of the outcrop boundary of the surfaces is defined by the wintertime data of Levitus [1982].

\section{OBSERVATIONS}

There are three major source regions that are feeding into the surfaces discussed here. First, there is the Antarctic region, which provides waters that are fresh and rich in nutrients. These waters invade the North Atlantic as the Antarctic Inter-

TABLE 1. Potential Density Surfaces Used in This Study

\begin{tabular}{|c|c|c|c|c|c|c|}
\hline$\sigma_{2}$ & $\sigma_{\theta}$ & $\sigma_{4}$ & Depth, $m$ & Description & \multicolumn{2}{|c|}{ Water Masses } \\
\hline 36.4 & $27.30-27.62$ & $44.79-45.09$ & $800-1100^{*}$ & Salinity minimum & \multirow{2}{*}{\multicolumn{2}{|c|}{$\begin{array}{l}\text { Antarctic Intermediate } \\
\text { Mediterranean Outflow }\end{array}$}} \\
\hline 36.6 & $27.46-27.79$ & $45.02-45.33$ & $1100-1200^{*}$ & $\begin{array}{l}\text { Salinity maximum } \\
\text { (eastern basin) }\end{array}$ & & \\
\hline 36.85 & $27.73-27.87$ & $45.44-45.57$ & $1500-1600^{*}$ & $\begin{array}{l}\text { Silica maximum } \\
\text { Salinity maximum } \\
\text { (western basin) }\end{array}$ & \multicolumn{2}{|c|}{ Labrador Sea, Upper NADW } \\
\hline 36.95 & $27.81-27.86$ & $45.63-45.68$ & $1950-2350$ & Oxygen maximum & Middle NADW & DSOW, ISOW \\
\hline 37.0 & 27.84-27.87 & $45.72-45.75$ & $2300-2800$ & Oxygen maximum & Middle NADW & DSOW, ISOW \\
\hline 37.05 & $27.87-27.88$ & $45.81-45.82$ & $2950-3300$ & & & DSOW, ISOW \\
\hline
\end{tabular}

NADW, North Atlantic Deep Water; DSOW, Denmark Strait Overflow Water; ISOW, IcelandScotland Overflow Water.

*Depth range of the surface south of the steeply sloping region leading to the outcrop. 
DE.PIH $[M]$

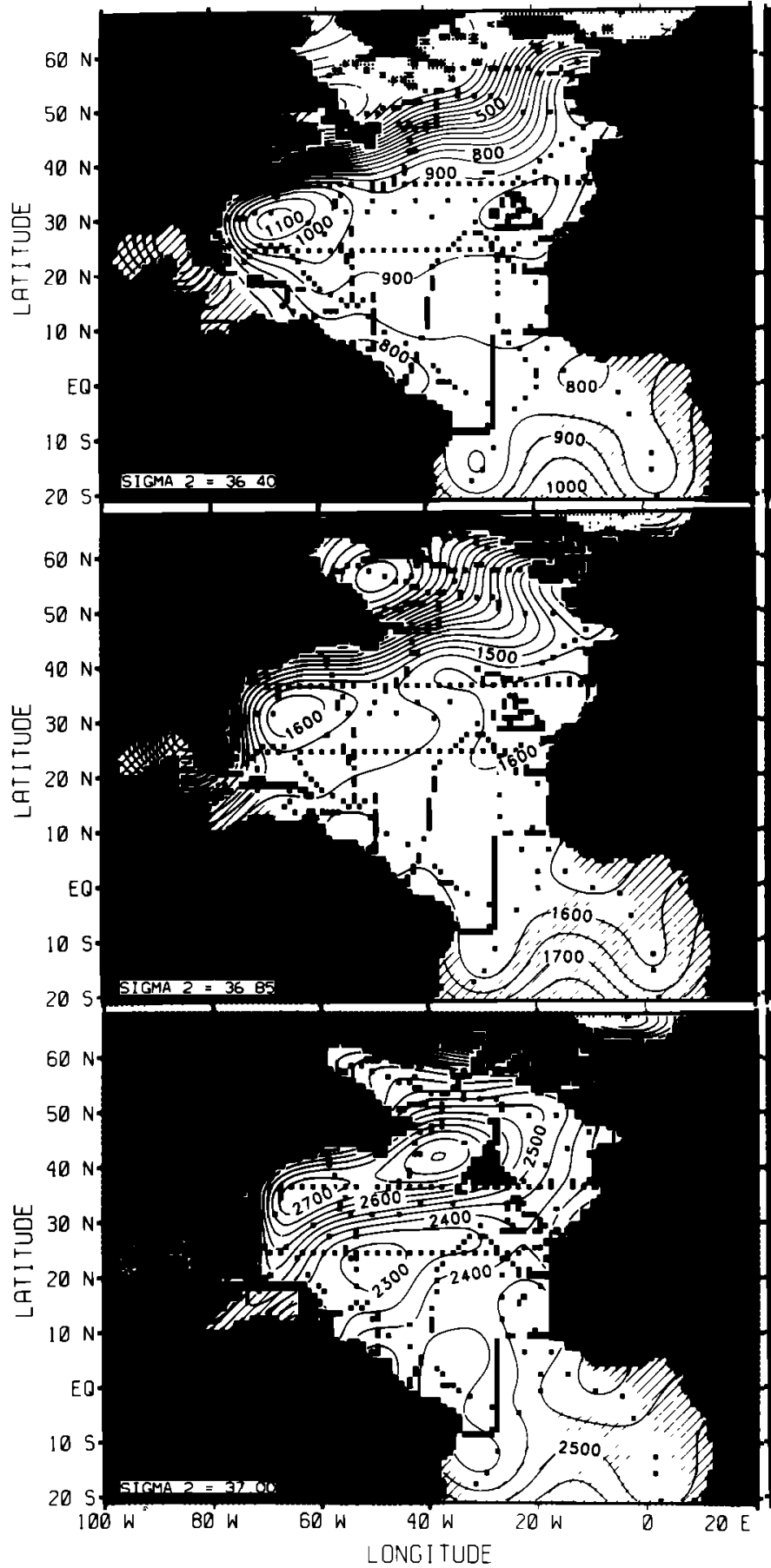

DEPIH $\{M\}$

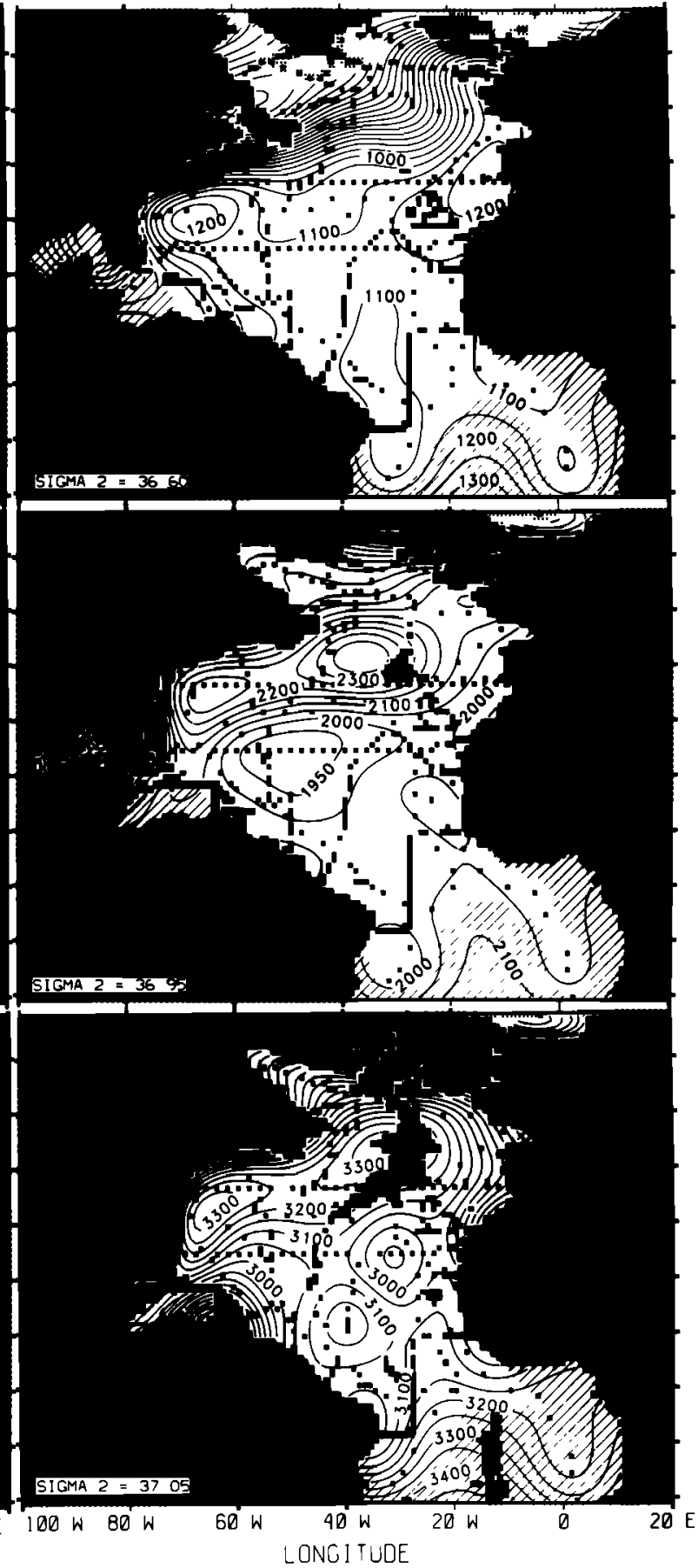

Fig. 6. Depths of the potential density surfaces. Stars denote stations, stippling denotes outcrops as determined from the ocean atlas by Levitus [1982], and cross hatching denotes areas with large estimated errors. On this figure, it denotes regions with errors greater than, from top, $150,150,150,200,250$, and 300 , respectively.

mediate and Bottom waters, the former of which appears on surfaces $\sigma_{2}=36.4$ and 36.6. Second, there is the Mediterranean Sea, which provides saline waters. The Mediterranean Sea imports the nutrient-poor surface waters of the Atlantic and exports waters with salinity increased through excess evaporation. Hence the Mediterranean Outflow Water is poor in nutrients. Its presence is most strongly felt on the $\sigma_{2}=36.6$ surface. Last, there are outcrops and deep water formation regions in the northern North Atlantic, which in- cludes the Labrador, Norwegian, and Greenland seas and whose waters are of intermediate salinity and poor in nutrients.

The contrast in salinity between the source waters from the north and the south is much less marked than between either of the two and the Mediterranean Outflow Water. Hence the distribution of salinity in the North Atlantic reflects strongly the presence of the Mediterranean Outflow Water with its high salinity value. On the other hand, there is no great differ- 
SAL INITY (PERMIL)
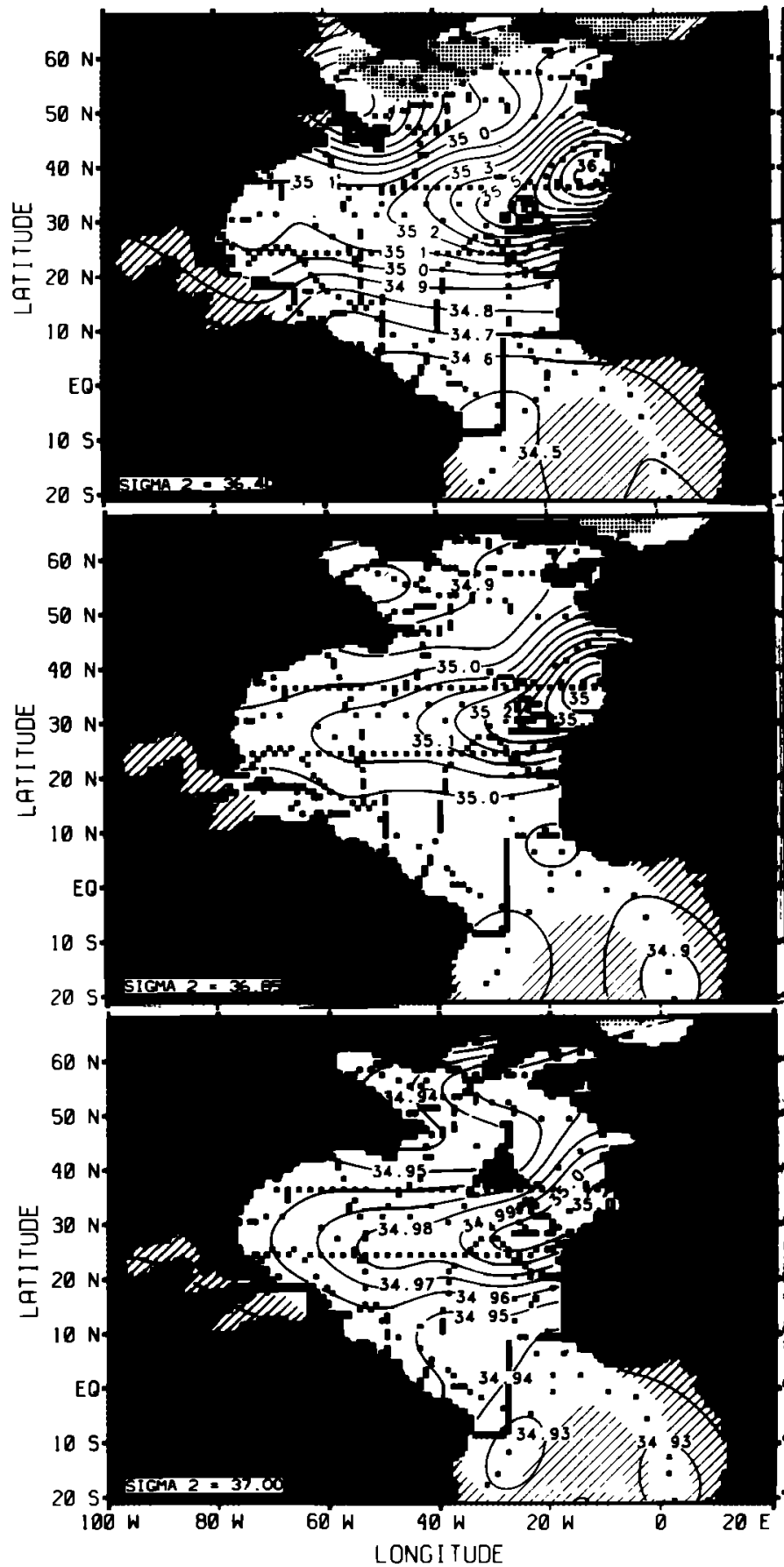

SAL INITY (PERMIL)
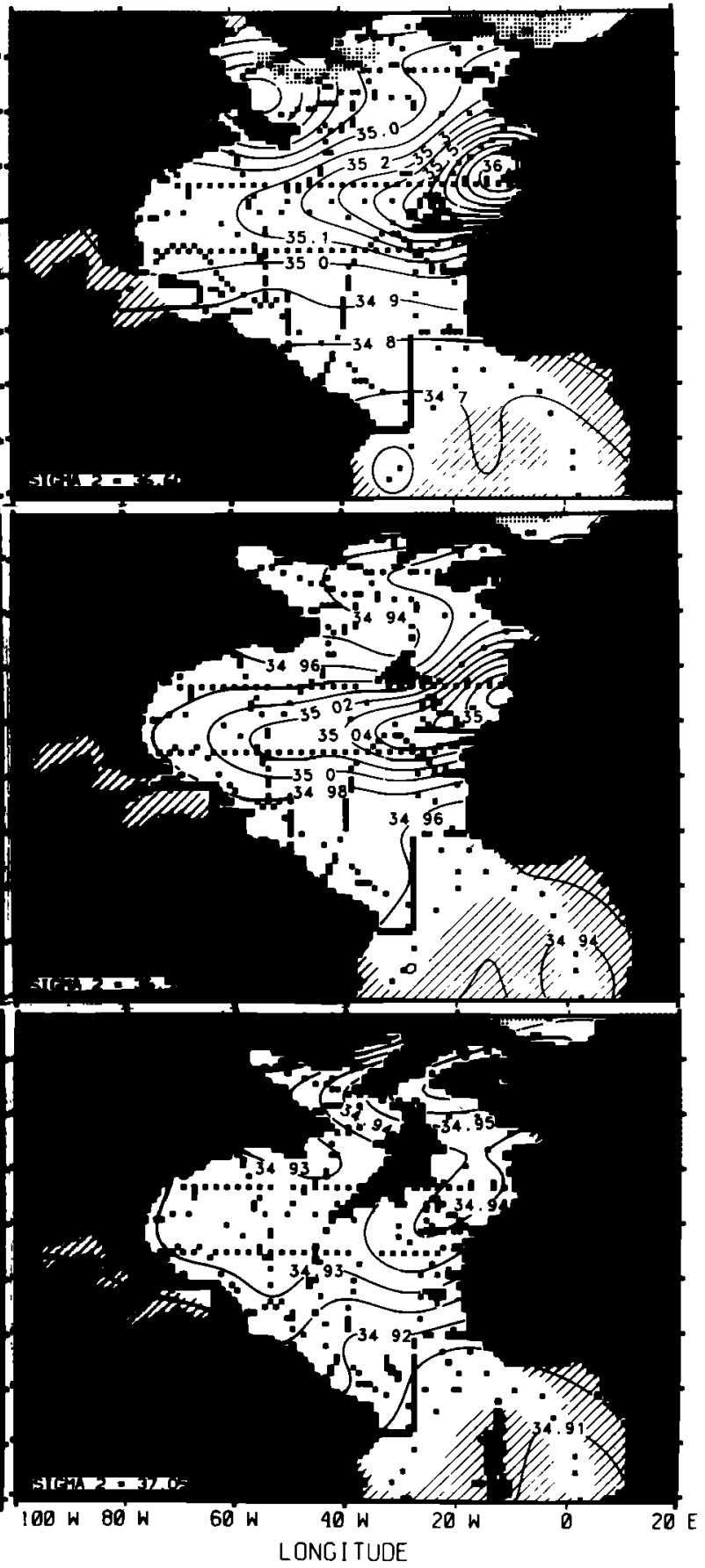

Fig. 7. Salinity on the potential densily surfaces. For symbols used, see Figure 6. Cross hatching denotes areas with estimated errors greater than, from top, $0.2,0.2,0.1,0035,0.025$, and $0.018 \%$, respectively.

ence in the nutrient level between the northern source and the Mediterranean Outflow Water. Consequently, the Mediterranean Outflow Water is hardly identifiable from the nutrient distribution. The contrast in nutrients is most strong between the two sources in the North Atlantic and the Antarctic source, especially in the equatorial region. Moreover, there are strong signals of nutrient regeneration, which create very different patterns on the nutrient distribution from the salinity distribution.

\section{Salinity}

As was mentioned already, the most conspicuous feature on the salinity maps is the tongue of salty waters from the Medi- terranean Sea. This can be seen clearly on all the surfaces except the deepest one $\left(\sigma_{2}=37.05\right)$. We start with a description of salinity fields on the top two surfaces, $\sigma_{2}=36.4$ and 36.6 (Figure 7). These surfaces show the Mediterranean Outflow Water tongue centered between $30^{\circ}$ and $35^{\circ} \mathrm{N}$. Salinity is lower toward the south and into the Labrador Sea. The northward protrusions of the isohalines east of the Antilles may suggest that the flow of the Antarctic Intermediate Water into the North Atlantic is concentrated at the western boundary. For the sake of comparison with deeper surfaces, we may note that the range of salinity on this and the next surface is quite large. In particular, note the "tail" of high-salinity water from the Mediterranean Sea that appears on the plots of nutrients 
OXYCEN (MICROMOLES/KG)

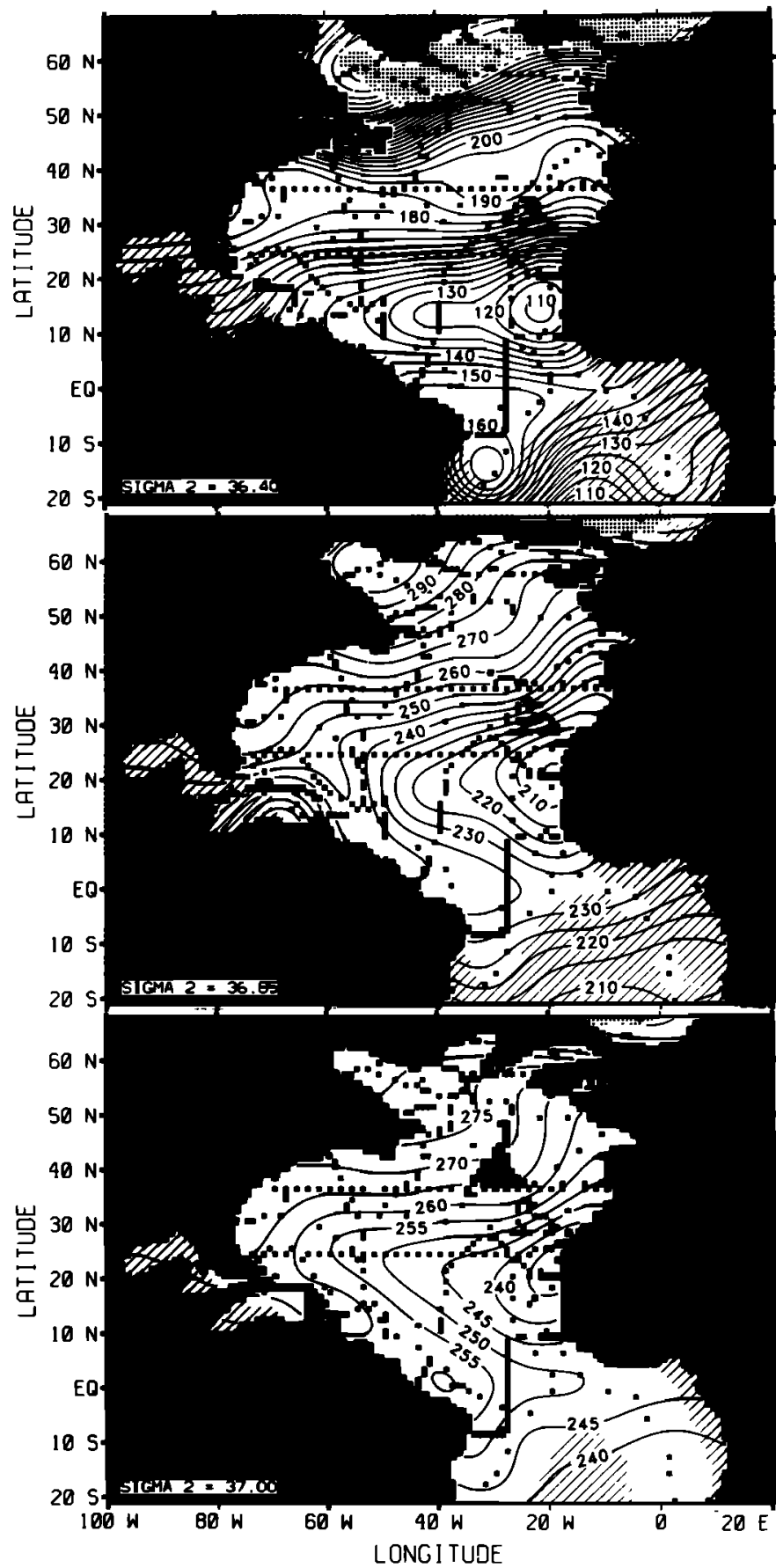

OXYGEN IMICROMOLES/KC

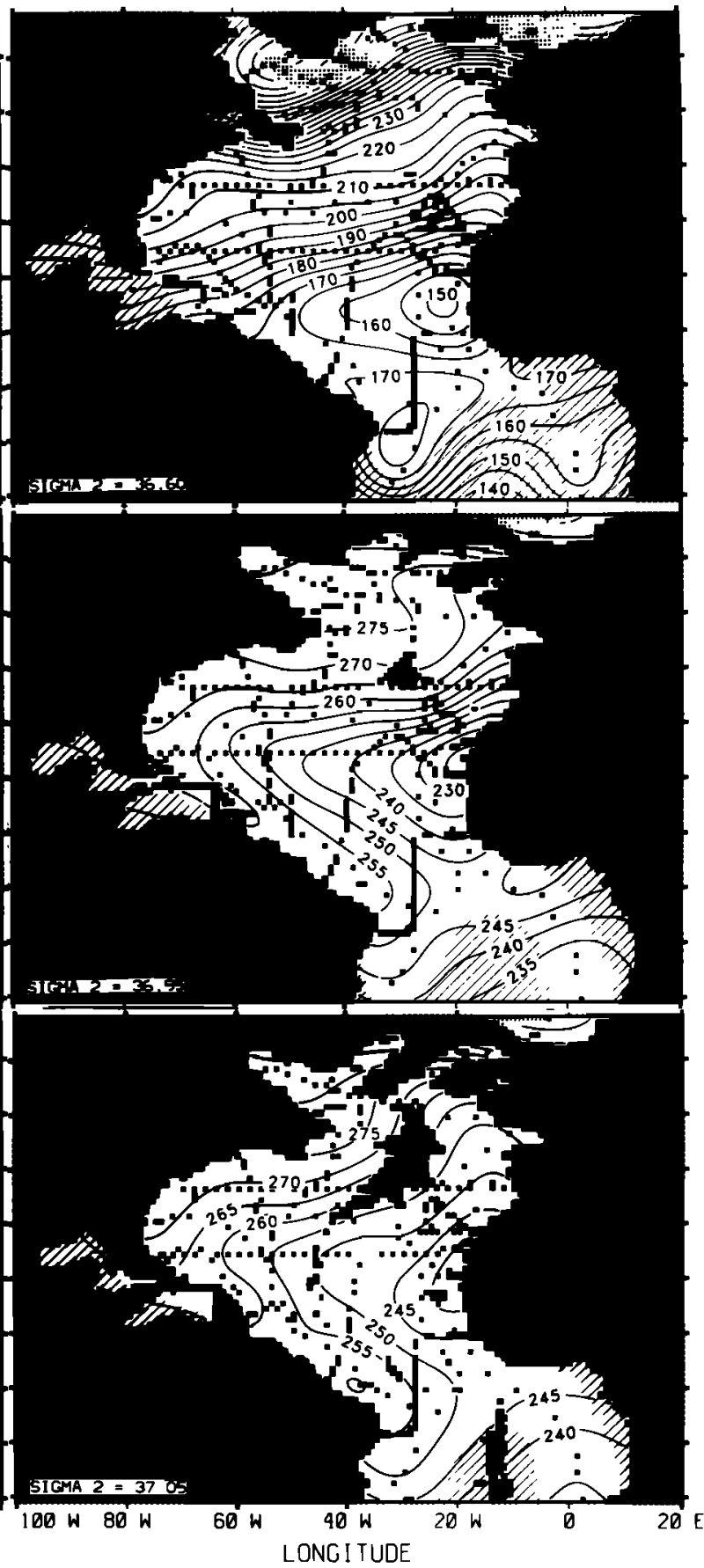

Fig. 8. Oxygen on the potential density surfaces. For symbols used, see Figure 6. Cross hatching denotes areas with estimated errors greater than, from top, $20.0,15.0,10.0,10.0,10.0$, and $10.0 \mu \mathrm{mol} / \mathrm{kg}$, respectively.

against salinity (Figures 10,12 , and 14 ) for this and the next surface. The northern source water too shows a large range in salinity, with waters from the eastern part of the outcrop showing in general a higher salinity.

The next surface, $\sigma_{2}=36.85$, lies in the core of the Upper North Atlantic Deep Water, which is a mixture of the oxygenrich Labrador Sea Water and the saline Mediterranean Outflow Water. The qualitative pattern of the salinity field is similar to the surfaces above, with the Mediterranean Outflow Water tongue dominating the scene. However, note the drastic reduction in salinity of the Mediterranean Outflow Water. Consequently, the range of salinity to be found on the surface is narrower than on the surfaces above. In fact, this surface lies close to the maximum depth to which the Mediterranean water is supposed capable of sinking [Pingree, 1972]. Also note that the core of the tongue has shifted slightly to the south, now at $30^{\circ} \mathrm{N}$. There is a local minimum of salinity in the Labrador Sea, indicating the source region of the Labrador Sea water.

The next two surfaces we discuss are at $\sigma_{2}=36.95$ and 37.0. They lie within the Middle North Atlantic Deep Water of Wust [1935]. The range of salinity becomes even narrower as one goes deeper. However, the pattern of salinity distribution, especially the apparent tongue of high-salinity water that 

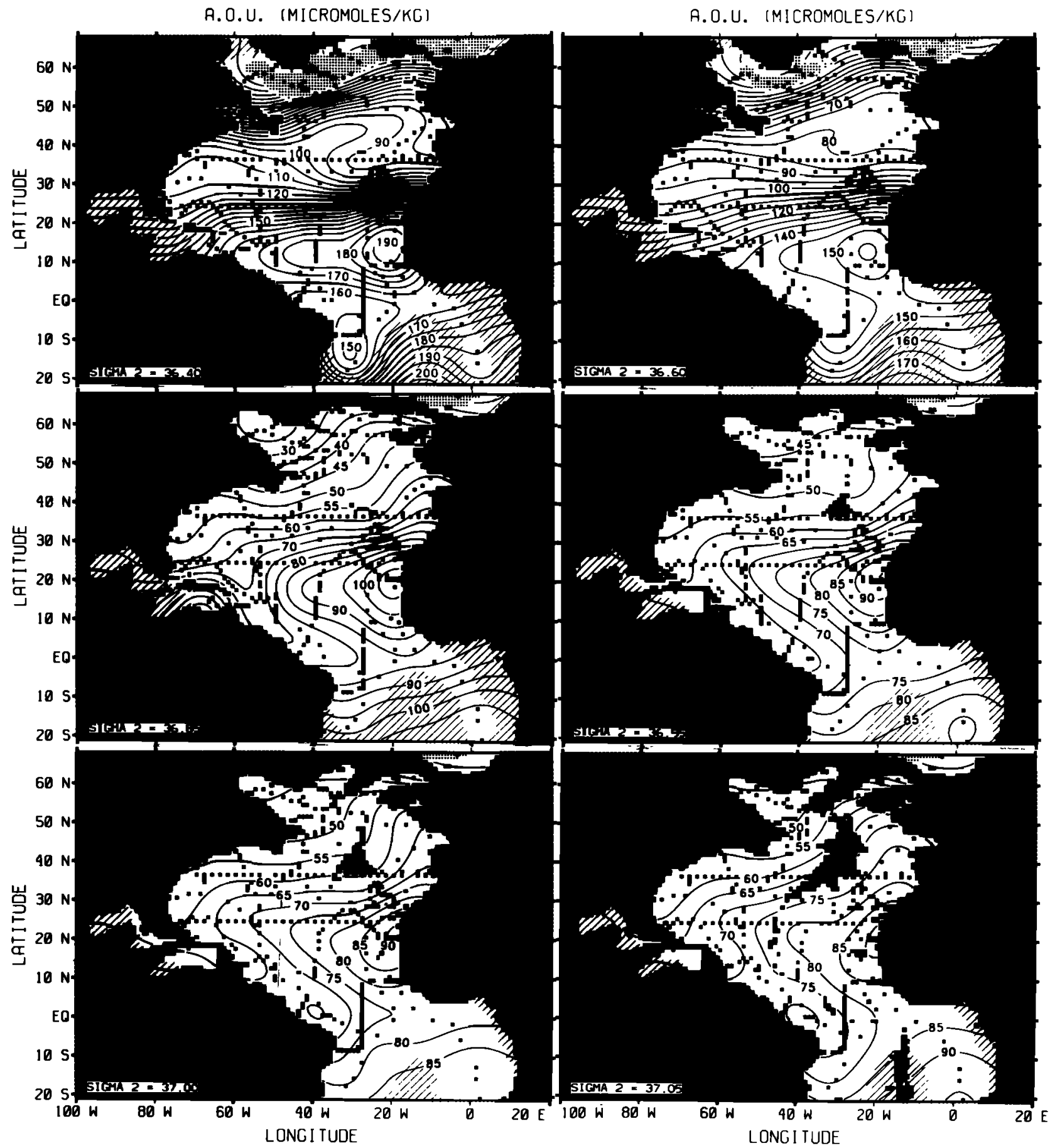

Fig. 9. Apparent oxygen utilization on the potential density surfaces. For symbols used, see Figures 6 and 8.

straddles the subtropical North Atlantic, is quite similar to the shallower surfaces, except that the tongue has shifted further south still, with the core of the tongue at about $27^{\circ} \mathrm{N}$. It seems reasonable to argue that much of the high-salinity water that appears on this surface, and also the surface above, $\sigma_{2}=$ 36.85 , comes not from direct entry of the Mediterranean water but from an in situ mixing down of high-salinity waters from above by salt fingering. This point shall be discussed further below.

In the northern North Atlantic, we see higher salinity values in the eastern basin, which comes from the higher salinity values for the Iceland-Scotland Overflow Water than for the Denmark Strait Overflow Water. This high-salinity water seems to cross into the western basin as a tongue between the Reykjanes Ridge and the Azores Plateau. Low-salinity values occur along the western boundary of the western basin down to the Grand Banks. The maps show this low-salinity water spreading eastward from the Grand Banks, but there are no stations to substantiate this feature in the region of the Azores Plateau. However, Worthington and Wright's [1970] atlas of the deep North Atlantic does show a region of low-salinity water between the Grand Banks and the Azores Plateau.

The last surface, $\sigma_{2}=37.05$, lies between the Middle and the Lower North Atlantic Deep Waters and it shows a further change in salinity patterns. The Mediterranean Outflow Water tongue has disappeared from the western basin where salinity 

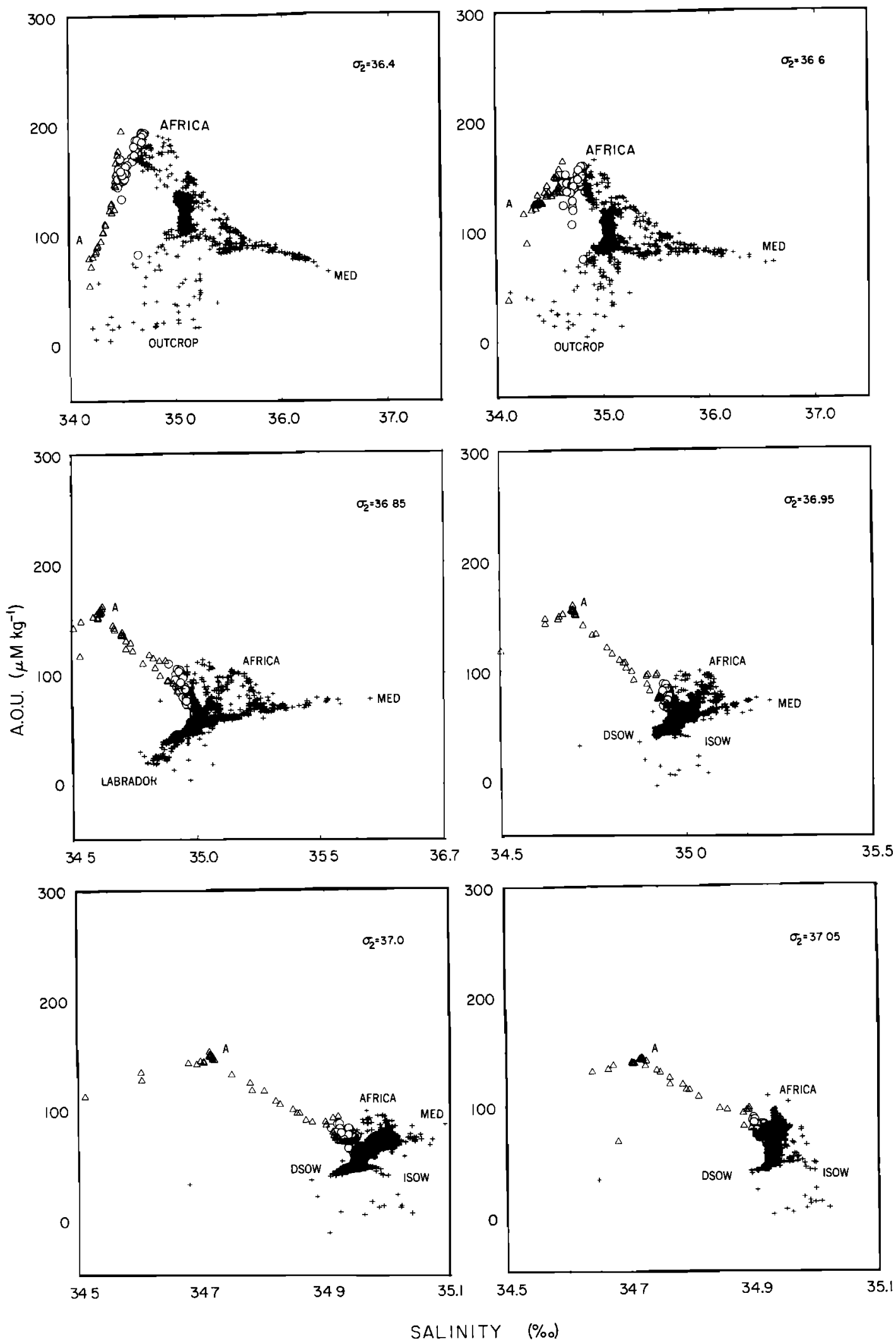

Fig. 10. AOU versus salinity. Triangles denote stations south of $10^{\circ} \mathrm{S}$, circles denote stations between $10^{\circ} \mathrm{S}$ and $10^{\circ} \mathrm{N}$, and crosses denote stations north of $10^{\circ} \mathrm{N}$.

is largely homogeneous, although a vestige of it in the form of a local salinity maximum remains in the eastern basin. Highsalinity waters appear in the northernmost parts of the eastern basin and seem to leak out to the northernmost western basin through the Gibbs fracture zone at $52^{\circ} \mathrm{N}-30^{\circ} \mathrm{W}$. Indeed, the saltiest water that enters this surface is the Iceland-Scotland overflow that enters at the northern end of the eastern basin.

South of $20^{\circ} \mathrm{N}$ at $\sigma_{2}=37.05$, salinity values decrease to the 
SILICATE IMICROMOLES/KG

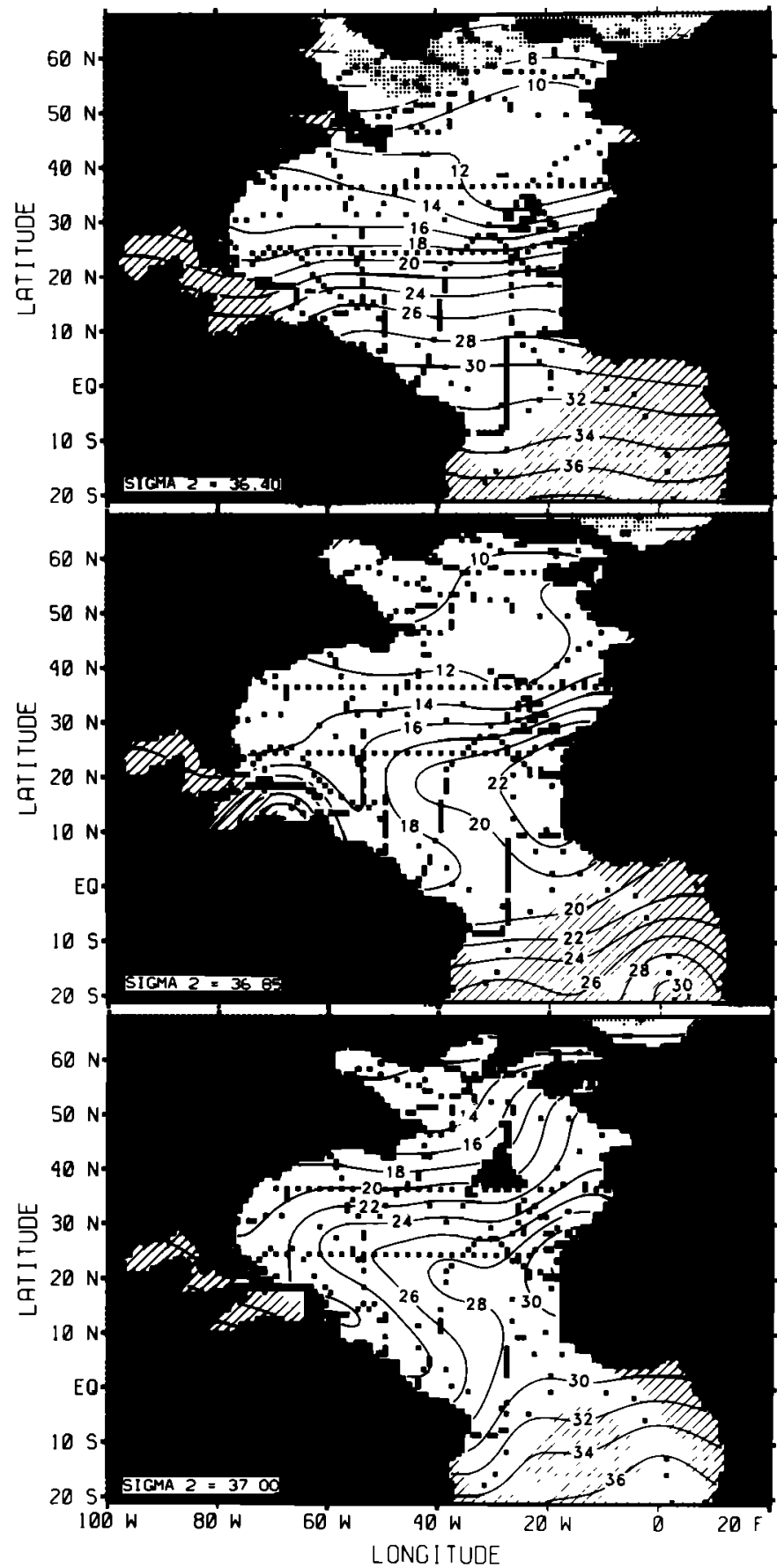

SILICATE (MICROMOLES/KG)

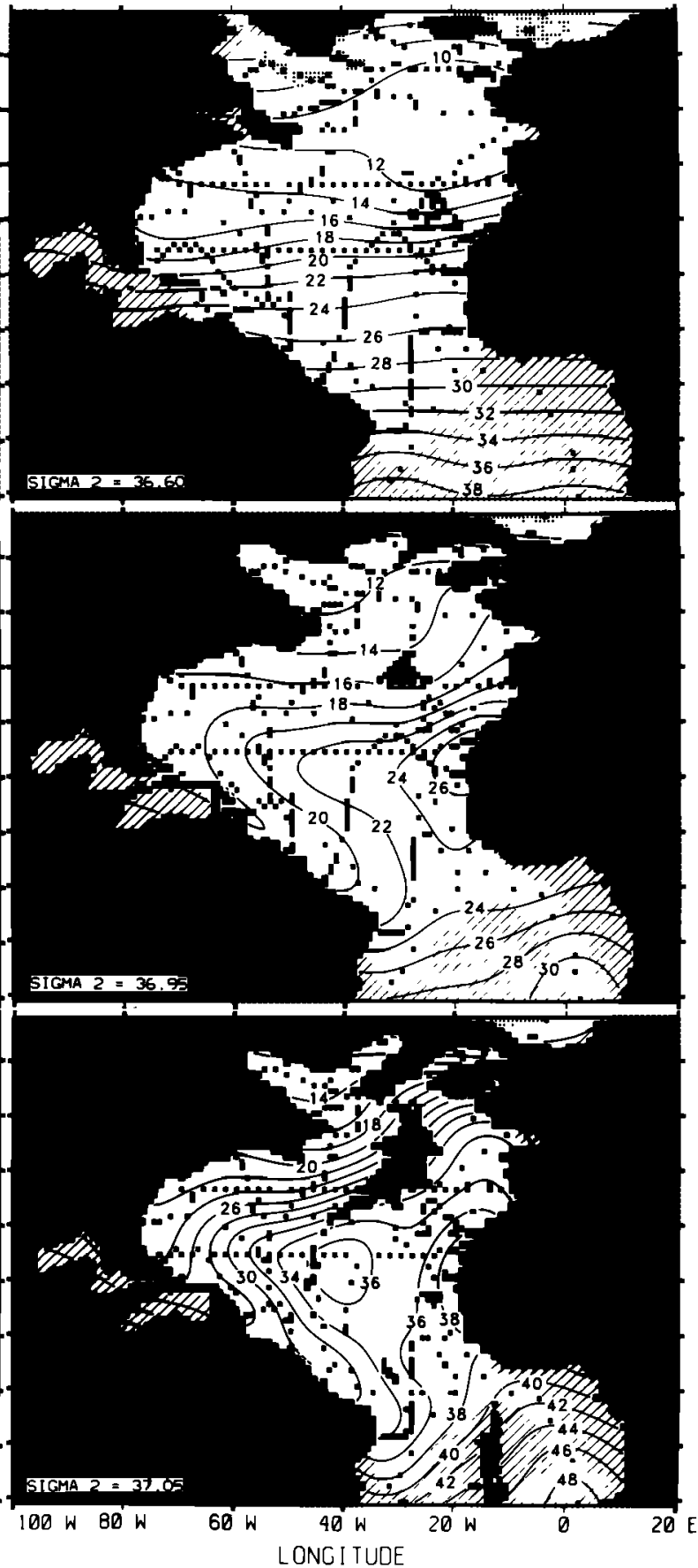

Fig. 11. Silica on the potential density surfaces. For symbols used, see Figure 6. Cross hatching denotes areas with estımated errors greater than, from top, $2.0,2.0,2.5,2.5,3.0$, and $4.0 \mu \mathrm{mol} / \mathrm{kg}$, respectively.

south. The undulations on the isohalines in this region, similar to the pattern on the shallowest surface, indicate that there is a southward flowing deep western boundary current carrying the saline waters from the north.

\section{Oxygen, $A O U$}

In contrast to the salinity fields, the distribution of oxygen shows very little of the Mediterranean influence. The oxygen and AOU maps (Figures 8 and 9, respectively) show that, on the two shallowest surfaces, the dominant feature is the strong oxygen minimum/AOU maximum off Africa and its westward extension that was discussed in our previous paper [Kawase and Sarmiento, 1985]. This seems to be due to a strong oxygen consumption from the regeneration of falling organic material, and it shows itself as an upward warping of the mixing line between the Antarctic waters and the northern waters on the AOU-salinity plot (Figure 10). North of this, the oxygen level increases (AOU decreases). It is interesting that there is a belt of relatively low oxygen gradient between $30^{\circ}$ and $45^{\circ} \mathrm{N}$, with an indication of anticyclonic flow to the east near Europe.

At $\sigma_{2}=36.85$ the oxygen/AOU distribution changes significantly. First of all, note the overall abundance of oxygen (low 

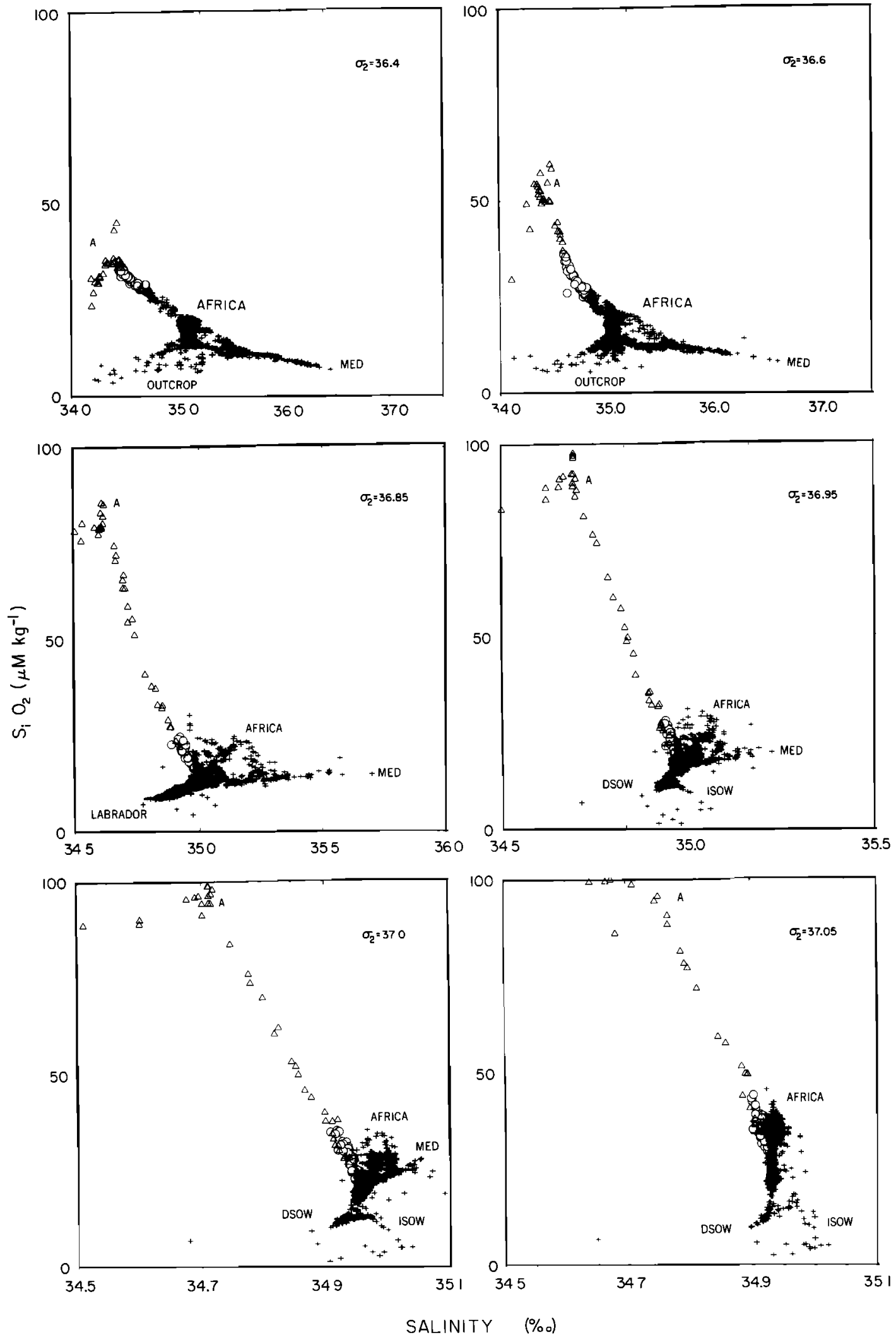

Fig. 12. Silica versus salinity. For symbols used, see Figure 10.

AOU values) on this surface compared with the surfaces above. The oxygen map (Figure 8) shows clearly a western boundary current carrying the oxygen-rich Upper North Atlantic Deep Water to the south as found by Wust [1935] and recently confirmed in the transient tracer fields such as freon [Weiss et al., 1985]. The freon field shows a greater concentration at the depth of this surface than at somewhat shallower depths, indicating that this surface is better ventilated 
N] TRATE IMICROMOLES/KG

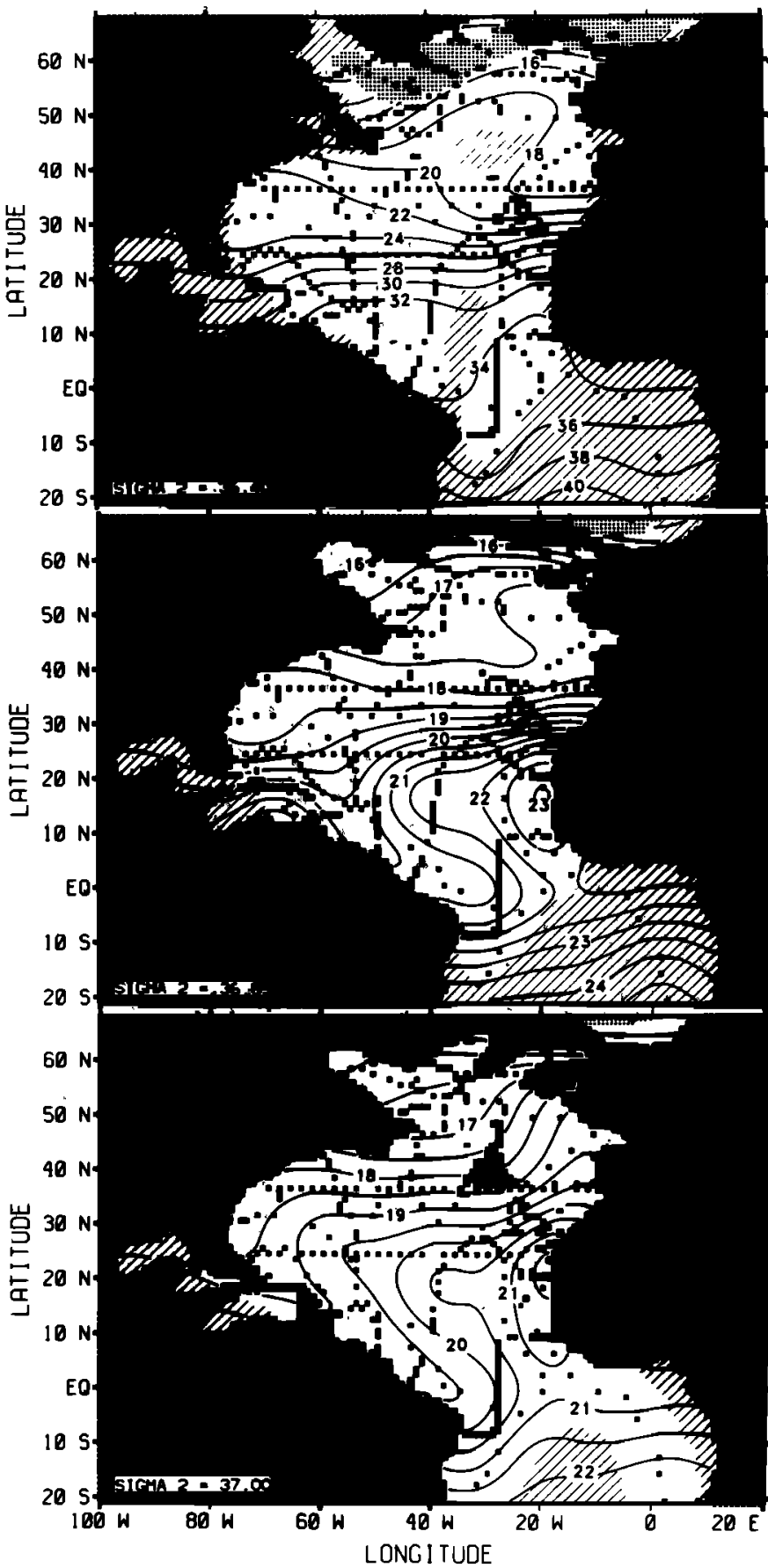

NITRATE (MICROMOLES/KG)

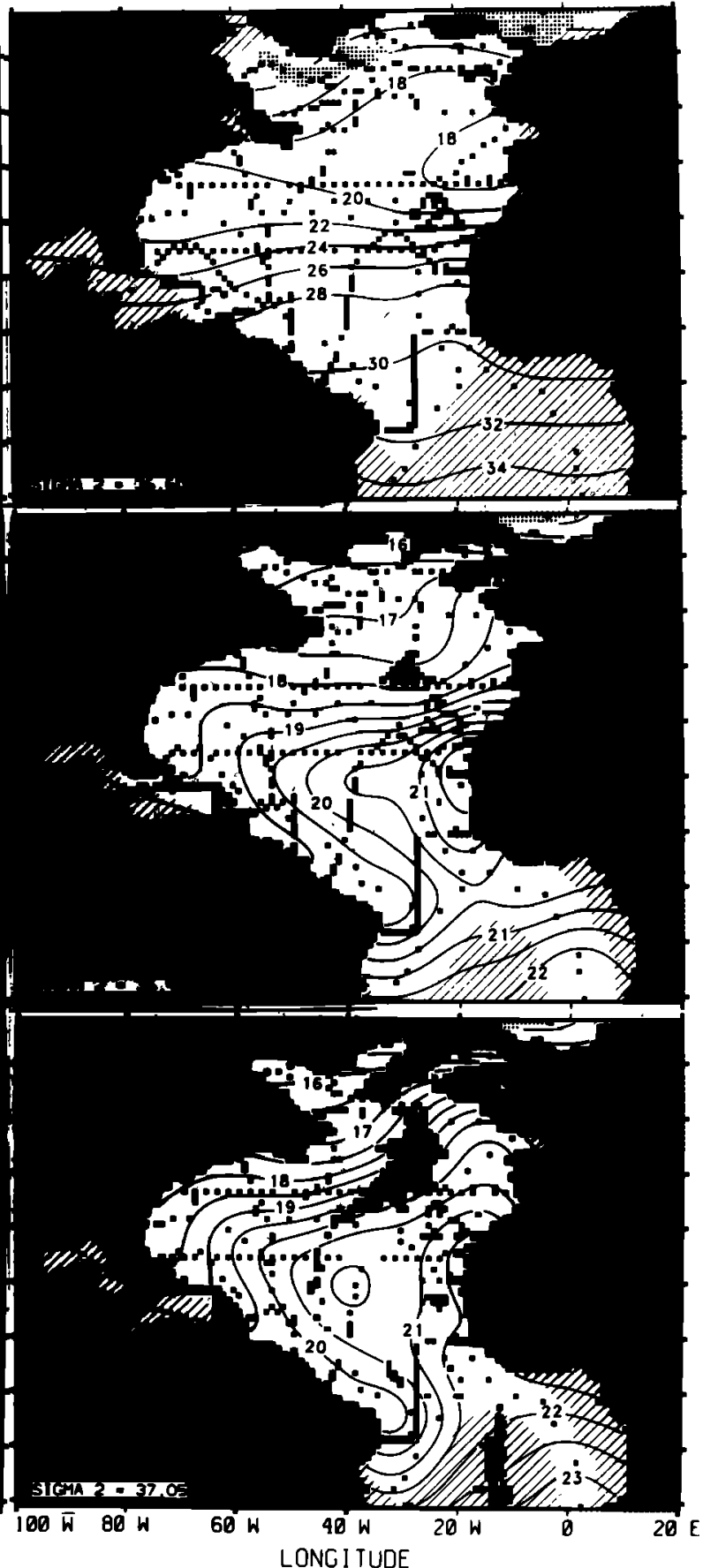

Fig. 13. Nitrate on the potential density surfaces. For symbols used, see Figure 6. Cross hatching denotes areas with estimated errors greater than, from top, $2.0,1.5,1.0,1.0,1.0$, and $1.0 \mu \mathrm{mol} / \mathrm{kg}$, respectively.

than the surfaces above. Since the newly formed deep water could have AOU as high as $30 \mu \mathrm{moles} / \mathrm{kg}$, this leaves very little room for oxygen consumption in the western basin. At the equator, a part of the deep western boundary current appears to turn eastward along the equator, a feature that also was noted by $W$ ust [1935]. The freon data [Weiss et al., 1985] also show an appearance of high-freon water at a depth close to ours at the equator.

North of $40^{\circ} \mathrm{N}$, oxygen levels increase rapidly toward the northwest. However, one sees relatively low oxygen levels close to the European coast. This is suggestive of advection of oxygen-poor water from the south as an eastern boundary current. Ivers [1975] recognizes such a current from geostrophic shear and salinity and calls it the Mediterranean Undercurrent [see also Reid, 1979]. In the tropics, oxygen levels decrease (AOU increases) away from the western boundary toward the oxygen minimum/AOU maximum off the west coast of Africa. It is interesting that this minimum in oxygen is much weaker than the comparable feature on the shallower surfaces and is also shifted northward from $10^{\circ} \mathrm{N}$ on shallower surfaces to about $20^{\circ} \mathrm{N}$.

The plot of AOU against salinty (Figure 10) also shows that 

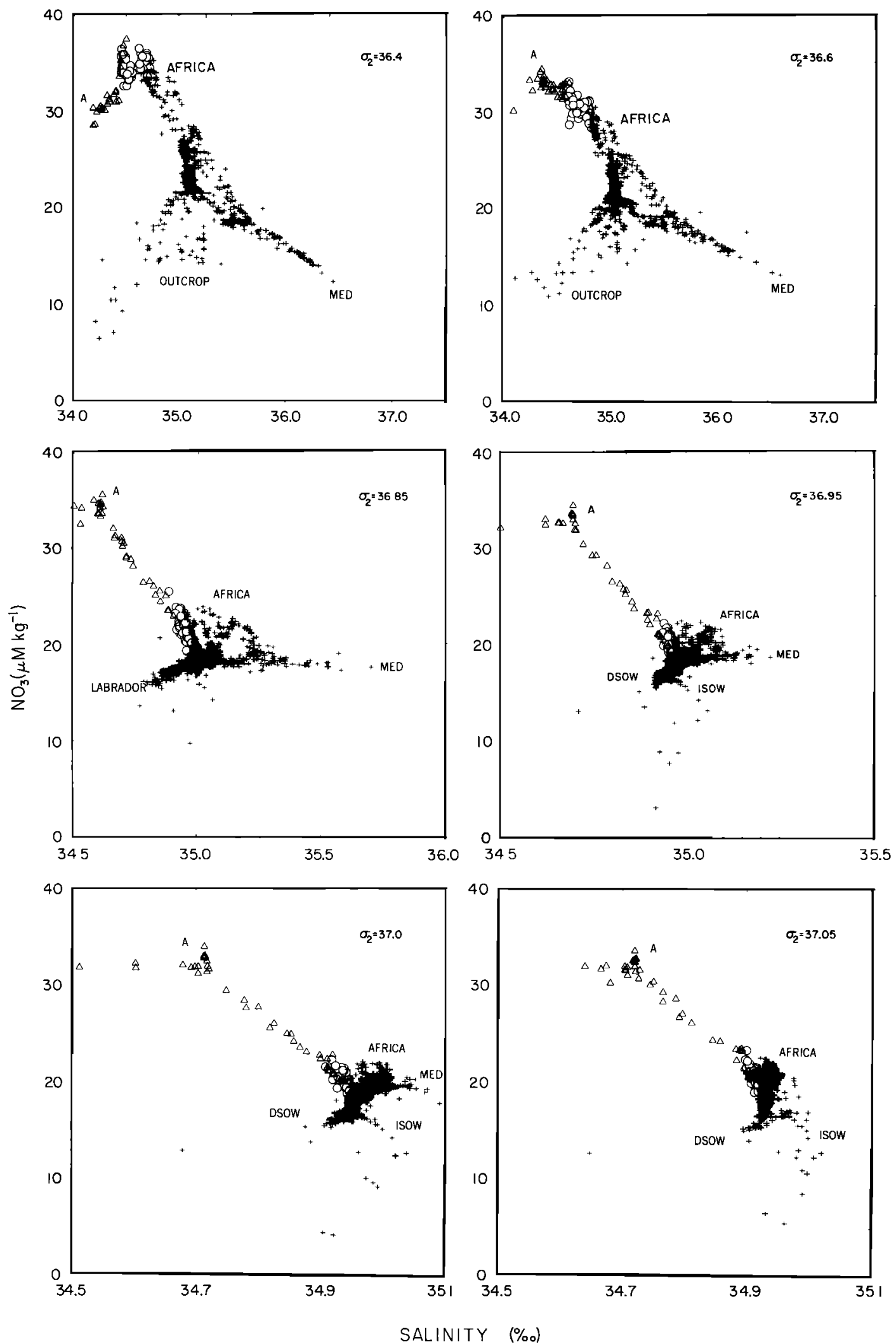

Fig. 14. Nitrate versus salinity. For symbols used, see Figure 10.

the $\sigma_{2}=36.85$ level is quite different in hydrography from the surfaces above. The conspicuous signal of oxygen consumption in the mixture of the northern gyre and the South Atlantic waters that was seen on the salinity-oxygen plots for the shallower surfaces has disappeared: instead, the cluster of points on the salinity-oxygen plot falls within a triangle spanned by (1) Labrador Sea water at the bottom, (2) Mediterranean water to the right, and (3) Antarctic water at the 
top. The northern source water does not have a wide range of salinity, as is the case for shallower surfaces. Instead, there is a single water source with narrowly defined salinity and AOU values. This source appears to be in the Labrador Sea. In addition to these, the waters from the oxygen minimum region off Africa form a fourth "end-member" between the Mediterranean water and water from the south.

Oxygen and AOU maps (Figures 8 and 9) for surfaces $\sigma_{2}=$ 36.95 and 37.0 show again the oxygen-rich deep western boundary current. North of $40^{\circ} \mathrm{N}$, oxygen levels are high and increase into the Labrador Sea, and even more toward the Icelandic Ridge. Again, relatively low oxygen levels are seen next to the European coast, indicative of the Mediterranean Undercurrent. We also note the strong indication of the deep western boundary current continuing along the equator. The oxygen minimum off Africa still appears at $20^{\circ} \mathrm{N}$ on these surfaces.

AOU versus salinity plots (Figure 10) for these surfaces show that the northern source water splits into two branches. The branch with higher salinity consists of waters from the Norwegian Sea, which flows over the Iceland-Scotland Ridge. The branch with lower salinity comes from the East Greenland Sea though the Denmark Strait. They also show that the oxygen minimum off Africa forms a significant fourth endmember. Clearly it is of great interest to identify the origin of this feature.

On the deepest surface, $\sigma_{2}=37.05$, most of the features in the oxygen and AOU fields are similar to the surface above, except that the equatorial continuation of the western boundary current is not as sharply defined. This surface comes close to the top of the Mid-Atlantic Ridge, and presumably the Ridge blocks eastward spreading of the water from the north.

\section{Silica and Nitrate}

Silica maps (Figure 11) also show a drastic change in silica distribution from surfaces $\sigma_{2}=36.4$ and 36.6 to surfaces $\sigma_{2}=$ 36.85 and below. In the shallowest two surfaces the silica field is strikingly symmetric zonally, and steadily increases to the south. An exception is the region of homogeneous silica concentration west of Europe, which is coincident with the region of apparent anticyclonic flows seen in the AOU distribution.

This strong zonal symmetry is broken for surfaces $\sigma_{2}=$ 36.85 and below. The deep western boundary current carrying the silica-poor Upper North Atlantic Deep Water is clearly visible. Once again, this water seems to leave the western boundary at the equator and spread eastward. North of about $35^{\circ} \mathrm{N}$, the silica level is uniformly low but decreases toward the north and into the Labrador Sea. For surfaces $\sigma_{2}=36.85$ and 36.95 , along the eastern boundary from Iberia to the Faeroe plateau, we can see a tongue of water that is relatively high in silica, indicating the Mediterranean Undercurrent. Silica levels are high toward the African coast, and at $\sigma_{2}=$ 36.95 and 37.05 one can see a silica maximum off West Africa, coincident with the oxygen minimum.

The surface $\sigma_{2}=37.05$ features an apparent interior silica maximum at about $28^{\circ} \mathrm{N}$ and $40^{\circ} \mathrm{W}$. This maximum can only be explained by cross-isopycnal mixing or in situ regeneration if it is indeed an interior feature; however, at this depth we are close to the top of the Mid-Atlantic Ridge, and it seems more reasonable to suppose that this feature lies on the flank of the ridge and that its origin is to the south, on account of its high silica value.

Silica-salinity plots (Figure 12) for these surfaces show that the southern source water for these surfaces is enormously rich in silica. Other source waters include the Labrador Sea for $\sigma_{2}=36.85$ and the Iceland-Scotland overflow and the Denmark Strait overflow for deeper surfaces, the Mediterranean and, again, the water from the region of silica maximum off West Africa, which is coincident with the oxygen minimum.

Nitrate maps for surfaces $\sigma_{2}=36.4$ and 36.6 (Figure 13) show a pattern that can be said to be intermediate to the AOU and silica distribution patterns. Although no isolated maxima in nitrate can be seen off Africa on these surfaces, the maps indicate that the level of nitrate is relatively high in waters around $10^{\circ} \mathrm{N}-20^{\circ} \mathrm{W}$. A broad front between $20^{\circ}$ and $30^{\circ} \mathrm{N}$ separates two regions of relatively weak gradients in nitrate concentrations, one being the equatorial region and the other to the north of the front. The former is absent in the silicate field, which increases steadily to the south through the tropics. This difference between nitrate and silicate is attributable to the fact that silicate-utilizing organisms (diatoms and radiolarians) occur in lesser proportion to other organisms in low-latitude waters than in polar waters. Nitrate concentration is increased in the tropics due to regeneration, forming a "plateau" of relatively high nitrate, while silicate distribution reflects simply the contrast between the northern and the southern source waters. As with AOU and silica, there is a region of particularly weak gradient west of Europe in the nitrate field, which however, contains a nitrate pattern indicative of an anticyclonic gyre.

Nitrate maps for surfaces $\sigma_{2}=36.85$ and below (Figure 13) and nitrate-salinity plots (Figure 14) show much the same features as noted in the AOU and silica maps and plots. The tongue of Upper North Atlantic Deep Water as a deep western boundary undercurrent and its continuation along the equator, the Mediterranean Undercurrent, the maximum in nitrate off Africa and its northward shift below $\sigma_{2}=36.85$ are all observed in the nitrate maps. They also suggest a southward advection of the water from the north to the east of the Azores Plateau and an apparent interior maximum in nitrate at $20^{\circ} \mathrm{N}$ to the east of the Mid-Atlantic Ridge at $\sigma_{2}=37.05$, although not as dramatically as silica does.

\section{DisCUSSION}

\section{Water Masses at Middepths}

The water masses at middepths were discussed by $W$ ust [1935], Worthington [1976], and Broecker and Takahashi [1980], among others. Wust's classification was based on tracer extrema in the interior ocean and was used as a guideline for surface selection in this study. The other three authors discussed water masses in terms of the source characteristics. According to them, the major sources are (1) the Mediterranean Sea, which provides salty waters with potential density up to $\sigma_{2} \sim 36.85$, (2) the Labrador Sea, which provides fresh waters with potential density similar to that of the Mediterranean Outflow Water, (3) the Norwegian Sea, which provides relatively salty waters for the deeper surfaces through the Iceland-Scotland overflow, and (4) the East Greenland Sea, which provides relatively fresh waters for the deeper surfaces through the Denmark Strait. All these northern sources have low nutrient levels, but the Mediterranean has a relatively high AOU level. In addition to these, there is (5) the Antarctic region, which provides the Antarctic Intermediate and Bottom waters, which are fresh and rich in nutrients.

These source characteristics are well depicted by our plots. Perhaps silica versus salinity plots (Figure 12) show them most clearly. For surfaces $\sigma_{2}=36.4$ and 36.6 , the dominant 
sources are the Mediterranean, which is salty and silica poor, the northern outcrop, which includes the Labrador Sea, which is fresh and silica poor, and the southern water, which is fresh and silica rich. The relatively wide range of salinity for the northern source water is due to the fact that the surface outcrops fairly extensively (see Figure 5) and a variety of surface waters in the northern North Atlantic can enter these surfaces.

As one goes deeper, we notice the following change in source water characteristics. The southern source becomes even more silica rich (a trend not shared by AOU and nitrate, which remain at the same levels); the Mediterranean source becomes less saline, indicating that this water is mixed down in situ from the main body of the Mediterranean Outflow Water above rather than flowing directly out of the Mediterranean Sea; the salinity range of the northern source collapses to an essentially unique value of about $34.8 \%$. This last point indicates that the northern source is no longer an extensive outcrop but is in a confined region of convection, in this case the Labrador Sea. This surface does outcrop in the Norwegian and Greenland seas, but waters from these regions seem to exercise little influence over the water mass characteristics of the main part of the Atlantic.

Further down, at $\sigma_{2}=36.95$ and below, we see that the northern source splits into the relatively salty $(35.0 \%$ ) IcelandScotland Overflow Water from the Norwegian Sea and the fresher (34.9\%) Denmark Strait Overflow Water from the East Greenland Sea. Talley and McCartney [1982] state that Wust's [1935] Middle North Atlantic Deep Water is the Labrador Sea water away from its source in the western basin of the Atlantic. However, we find that the surface $\sigma_{2}=36.95$, which lies within the upper oxygen maximum, which is Wust's definition of the Middle North Atlantic Deep Water, does not outcrop in the Labrador Sea. The property-property plots also indicate that the source region of the Middle North Atlantic Deep Water is within the Greenland and Norwegian seas.

In addition to these source waters, the plots indicate two other "source waters:" the downward bend on the mixing line between the southern source water and others on the silicasalinity plot at $\sigma_{2}=36.6$ was discussed by Kawase and Sarmiento [1985] and seems to be caused by in situ crossisopycnal mixing. The other is the relatively nutrient-rich water that occurs off Africa (see Figure 9). This will be discussed below.

\section{Circulation at Middepths}

The pattern of circulation for depths below the lower thermocline and above the crest of the Mid-Atlantic Ridge is not well understood and somewhat controversial. A particular controversy has evolved around how to interpret the gigantic tongue of salty water from the Mediterranean that straddles the Atlantic at these depths. Worthington [1976] argued that waters from the north cannot be crossing this conspicuous "ridge" of high-salinity water and thus argued for a tight recirculation gyre that is confined to the westernmost part of the ocean. On the other hand, Richardson and Mooney [1975] and Ivers [1975] argued, using isopycnal advective-diffusive balance of salt, that broad recirculation is not inconsistent with the presence of the tongue. Reid [1978, 1981] proposed a circulation scheme based on a geostrophic shear calculation where there is a westward flow along the core of the Mediterranean Water tongue with counterflows on both sides of the tongue. In this view, it may be said that the Mediterranean Outflow Water is not a passive feature embedded within the return flow but has its own circulation pattern associated with it. In this context, one must also mention that Armi and Haidvogel [1982] have pointed out the danger in automatically associating tonguelike features with advection by demonstrating that a spatially varying mixing coefficient can create tonguelike features.

It is worthwhile to compare recent studies done on the circulation in the North and Tropical Atlantic at these depths to the nutrient distribution. Most of the studies are concentrated in the western basin and are local in scope, the Gulf Stream in particular. There have been some studies of circulation at these depths in the eastern Atlantic. Pingree and Morrison [1973] and Reid [1979] discussed the northward advection of the Mediterranean Outflow Water. Leetmaa et al. [1977] discussed the basinwide transport of water in the eastern basin from $16^{\circ} \mathrm{N}$ to $32^{\circ} \mathrm{N}$ as well as north of $53^{\circ} \mathrm{N}$, and Saunders [1982] discussed it for the region in between. There have been a few studies of circulation on a basinwide scale [Reid, 1978, 1981; Wunsch and Grant, 1982].

The first thing to note when we compare the tracer fields with models of the circulation is that, while most models based on dynamical arguments emphasize the Gulf Stream system, the tracers show no clear evidence of an eastward flow at the latitude of the Gull Stream. Richardson [1985] has conclusively demonstrated that at $55^{\circ} \mathrm{W}$ the Gulf Stream in the time-average sense does extend to the bottom, and Hall and Bryden [1985] demonstrated the same at $68^{\circ} \mathrm{W}$. We may expect that, since the cross-flow scale of the deep Gull Stream found by these authors is small compared with the radius of influence used in our mapping, the signal of a deep Gulf Stream has been glossed over by the mapping. However, even in the original data, we see no pattern suggesting that a flow is present. This of course does not disprove the presence of a deep Gulf Stream, since if it is a tightly recirculating system of currents as proposed by Worthington [1976], we expect to see very little contrast in the nutrient field that would distinguish the flow system.

In the eastern basin, the tracer maps show contours running in the east-west to northeast-southwest direction and are therefore consistent with the general southwestward flow suggested by Saunders [1982]. Reid's [1981] steric height calculation of 2000 dbar relative to 3500 dbar also indicates a broad southwestward flow, which continues westward after crossing the Mid-Atlantic Ridge, much as the tracer concentration contours do. We also point out that the potential density surfaces $\sigma_{2}=36.95,37.0$, and 37.05 tilt down northward between $25^{\circ}$ and $35^{\circ} \mathrm{N}$ (Figure 6), indicating westward shear in the flow as one goes up in this region. The tracer distribution does not seem to be consistent with the alternating north-south flows of Wunsch and Grant [1982]. Presumably their model contains significant signals from transients such as Rossby waves, which do not amount to a net transport of water and therefore to which the tracer field is insensitive.

\section{Role of Mediterranean Outflow Water}

We have observed that the tongue of high-salinity water that appears to emanate from the Mediterranean maintains its appearance deep into the ocean, although its strength diminishes past $1200 \mathrm{~m}$ (Figure 7). We observe the tongue as deep as $\sigma_{2}=37.0(\sim 2400 \mathrm{~m}$ deep). Considering that the direct injection of the Mediterranean water stops at about $1600 \mathrm{~m}$ [Pingree, 1972], this is a remarkable vertical penetration.

It seems reasonable to suppose that the pattern of salinity distribution on the shallower surface is projected down to the deeper surfaces through strong in situ cross-isopycnal mixing. 

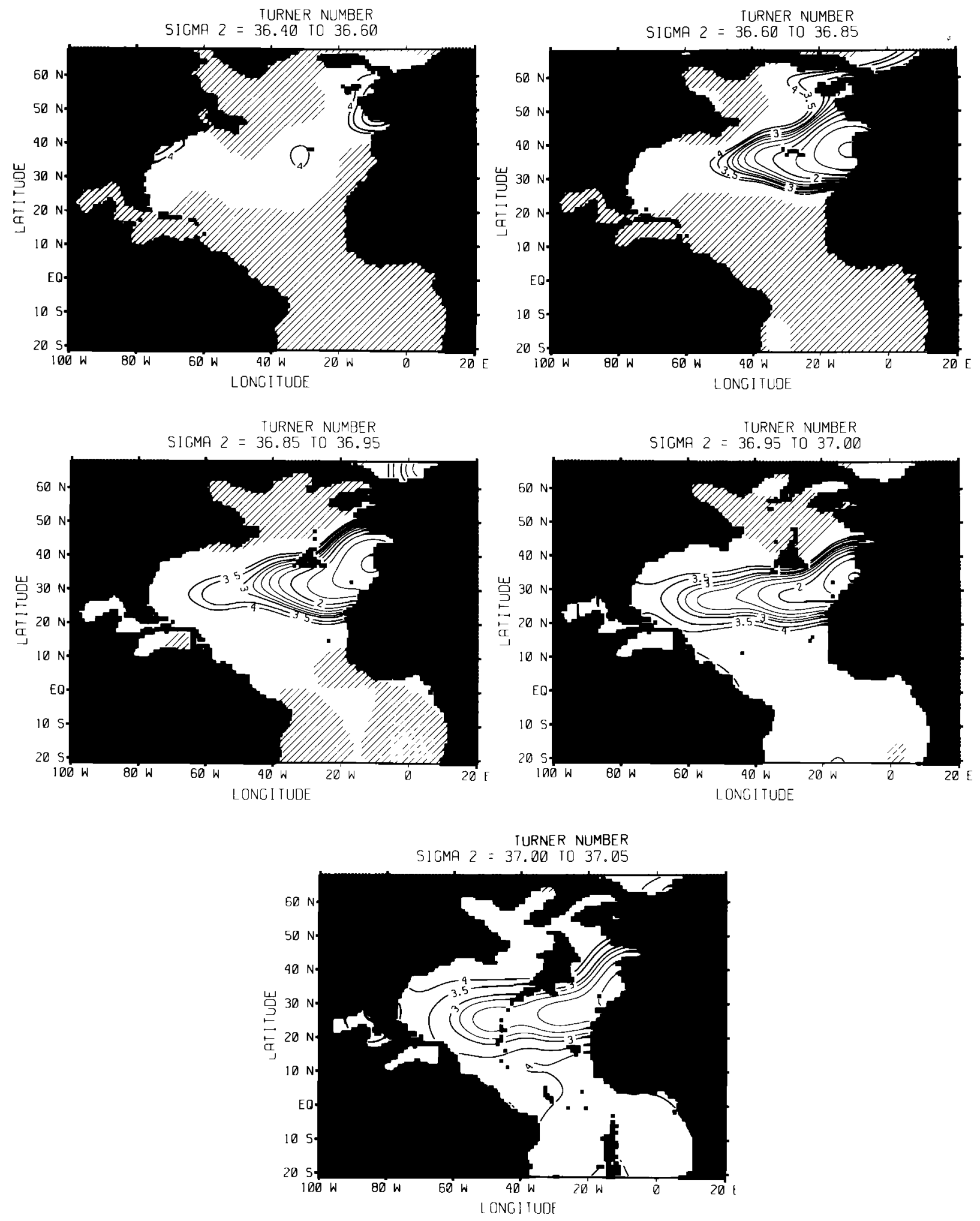

Fig. 15. Turner number $R_{\nu}=-\alpha \Delta T / \beta \Delta S$, where $\alpha=\partial \rho / \partial T, \beta=\partial \rho / \partial S$, and $\Delta T, \Delta S$ are potential temperature and salinity changes, respectively, between adjacent potential density surfaces.

Turner [1967] first drew attention to the potential for salt fingering in this region. The presence of salt fingering was substantiated with the observations of steplike features in temperature and salinity profiles underneath the Mediterranean Outflow Water [Tait and Howe, 1968; Zenk, 1970].

The distribution of the Turner number, $R_{\rho}=-\alpha \Delta T / \beta \Delta s$, which indicates the strength of salt finger activity, where $\alpha$ and $\beta$ are thermal and haline coeflicients of density change, respectively, and $\Delta T$ and $\Delta S$ are changes in the vertical of temperature and salinity, respectively, strongly supports this possibility. Figure 15 shows the distribution of $R_{\rho}$ between the surfaces we chose. Between $\sigma_{2}=36.6$ and 37.05 , for most of 

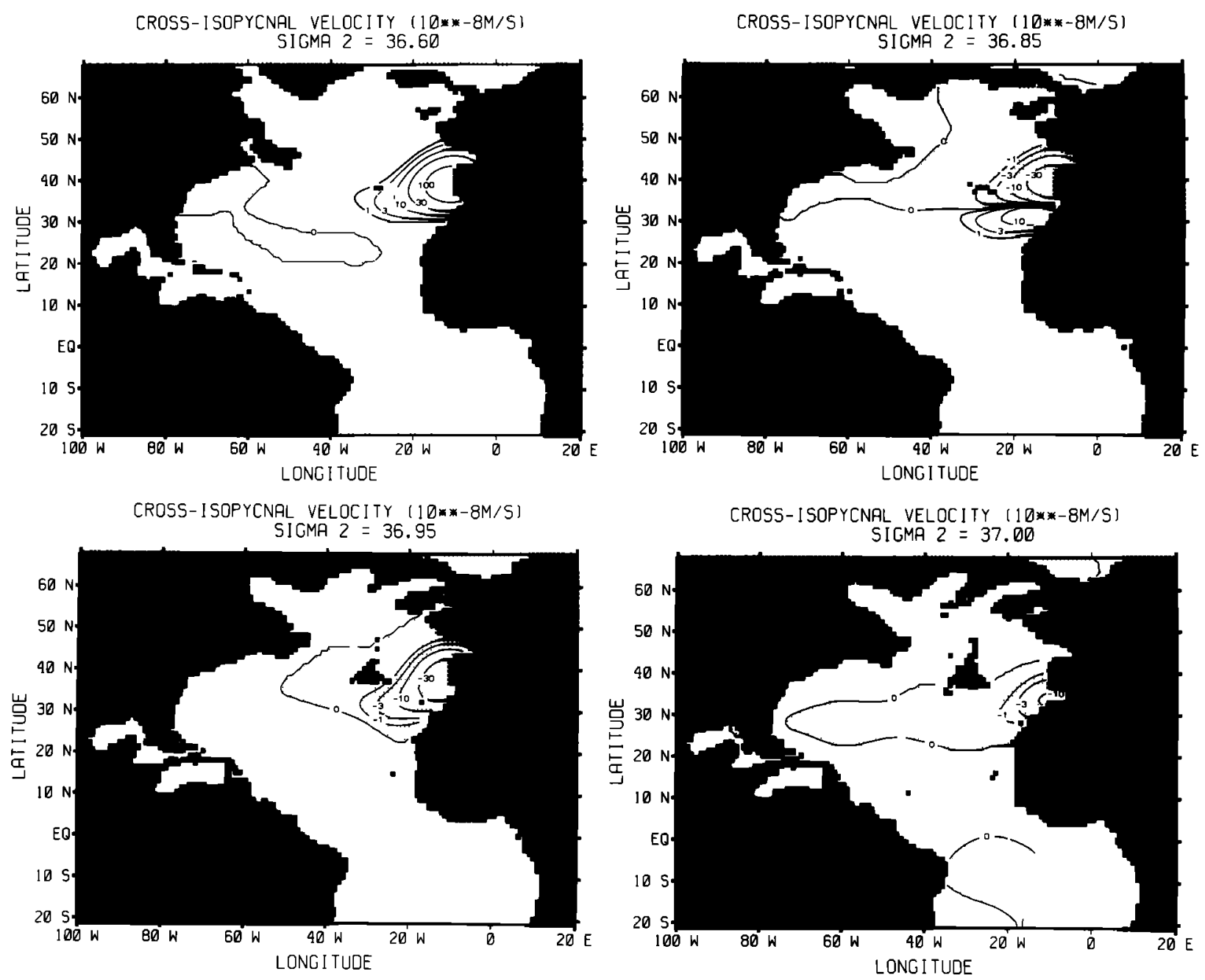

Fig. 16. Cross-isopycnal velocity on the potential density surfaces calculated from (4). Stipplıng denotes downwelling.

the subtropical North Atlantic, $\boldsymbol{R}_{\boldsymbol{\rho}}$ is positive, indicating that salt fingers can occur, and between $\sigma_{2}=36.6$ and 37.0 in the eastern basin close to the Gibraltar strait, we see $R_{\rho}$ values between 1 and 2 , indicating that salt fingering should be active in these regions. Schmitt's [1981] calculation shows tht salt fingers under the condition $R_{p}<1.6$ can provide salt diffusivity in excess of $7 \mathrm{~cm}^{2} / \mathrm{s}$. We conclude that the region below the Mediterranean Outflow Water is important as a field of cross-isopycnal mixing.

Such large salt finger activity can have consequences on large-scale circulation. Since salt fingers transport more salt than heat in the sense of bouyancy, it will tend to lighten the upper layers and to make the waters in the lower layers heavier (thereby lowering the potential energy of the water column, as it should, since salt fingering is essentially a form of convective instability). The resultant cross-isopycnal flow provides stretching for the layer in which salt fingers are taking place. If the scale of the salt fingering region is large, this stretching will result in a flow upgradient of the ambient potential vorticity $Q=f \rho_{z}$ due to the vorticity balance $f w_{z}=\mathbf{v} \cdot \nabla Q$, where $f$ is the Coriolis parameter, $\mathrm{u}$ is the isopycnal velocity, $w$ is the cross-isopycnal velocity, and $\rho_{z}$ is the vertical potential density gradient.

In light of this, we have attempted to calculate the crossisopycnal velocity due to the salt finger flux convergence of buoyancy. The diagnostic equation for the cross-isopycnal ve- locity $w$ is [McDougall, 1984]

$$
w=-\rho_{z}{ }^{-1}\left(\rho_{\mathrm{g}} F_{z}^{s}+\rho_{\theta} F_{z}{ }^{\theta}\right)
$$

where $\rho$ is the potential density, and $F^{s}$ and $F^{\theta}$ are fluxes of salt and potential temperature due to salt fingering. The subscript $z$ denotes the local vertical derivative, $\rho_{s}$ is the derivative of $\rho$ with respect to salinity with potential temperature fixed, and $\rho_{\theta}$ is the derivative of $\rho$ with respect to potential temperature with salinity fixed. The salt flux $F^{s}$ is diffusively parameterized:

$$
F^{s}=-D\left(R_{\rho}\right) S_{z}
$$

The salt finger mixing coefficient $D\left(F_{\rho}\right)$ is a function of $\boldsymbol{R}_{\rho}$. Its form was determined by fitting an exponential curve to the data compiled by Schmitt [1981, Figure 5] to be $D\left(R_{\rho}\right)=$ $\exp \left(-6.594 R_{p}+1.904\right)$ for $R_{p}>1$, and zero otherwise. The data are scanty, and this parameterization is the weakest element among the quantitative assumptions underlying this calculation. However, the qualitative conclusion does not depend strongly on the form of the parameterization for $F^{s}$. Rather, it depends on the differential heat and salt transport due to salt fingering. The temperature transport $F^{\theta}$ is related to $F^{s}$ through

$$
F^{\theta}=-\gamma \rho_{s} \rho_{\theta}^{-1} F^{s}
$$

where the nondimensional coefficient $\gamma$ is set at 0.7 [Schmitt, 
1979]. Substitution of (3) into (1) yields

$$
w=-(1-\gamma) \rho_{z}{ }^{-1} \rho_{s} F_{z}{ }^{s}
$$

Note that if $\gamma=1$, then $w=0$, since buoyancy fluxes due to heat and salt transports are exactly compensating. It is this departure from compensation that drives the cross-isopycnal velocity.

The calculation was done using the mapped salinity fields on potential density surfaces. Figure 16 shows the crossisopycnal velocity calculated for the surfaces $\sigma_{2}=36.6,36.85$, 36.95 , and 37.0. At $\sigma_{2}=36.6$, close to the European coast, the calculation results in significant upward velocities. This is because this surface, being in the core of the Mediterranean tongue, is losing salt through fingers and consequently waters on this surface are becoming lighter. On the other hand, at $\sigma_{2}=36.85$ and below, the velocity in the same region is significantly downward, since waters on this surface are acquiring salt from the flux convergence of salt due to fingers and are becoming denser. It is interesting to note that there is a region of upward velocity to the south of the downwelling region on the $\sigma_{2}=36.85$ surface. This results from the fact that the Mediterranean Outflow Water tongue has its axis shifting southward as one goes deeper (i.e., the tongue slants southward), as noted above.

The cross-isopycnal velocities at $\sigma_{2}=36.6$ and 36.85 along the European coast are comparable to that of Ekman pumping in the subtropical gyre region $\left(\sim 10^{-6} \mathrm{~m} / \mathrm{s}\right.$; Stommel [1979]), and the resultant divergence of cross-isopycnal flow between $\sigma_{2}=36.6$ and 36.85 is large enough to drive significant horizontal flow in the layer in between through vorticity stretching. For example, this process may supply a driving mechanism for the Mediterranean Undercurrent [Ivers, 1975] to continue flowing northward. This current is thought to be the major supplier of salt into the Norwegian Sea [Reid, 1979]. Although it is usually assumed that an outflow plume will turn right [Nof, 1978] in the northern hemisphere as a result of Coriolis force, it is not known whether such a plume may continue to follow the eastern boundary on the beta plane. In fact, it may be possible that an outflow plume will disperse into the interior ocean as Rossby waves [Philander and Yoon, 1982]. Vorticity stretching induced by salt fingers provides a mechanism for the Mediterranean Outflow Water to continue flowing northward. A rough estimate of the meridional velocity using the mapped field of cross-isopycnal velocity shown in Figure 16 and the simple vorticity stretching equation $\beta v=f w_{z}$ indicates that northward flow with speeds of up to about $1.6 \mathrm{~cm} / \mathrm{s}$ can be expected along the Portuguese coast. The raw station data from this region (TTO-NAS station 114) produce speeds as high as $13 \mathrm{~cm} / \mathrm{s}$. Of course, the above number for meridional flow speed is likely to be an overestimate, since the stretching can be partially compensated by a change in the thickness of the layer. Strictly speaking, $f w_{z}$ is proportional to the horizontal velocity component perpendicular to the local gradient of the potential vorticity $f \rho_{z}$.

\section{Deep Minimum in Oxygen, Maximum in AOU and Nutrients}

In these data we see the oxygen minimum/nutrient maximum west of Africa persisting down to the deepest surface. On nutrient-salinity plots, this water is seen to be clearly distinct from results of mixing of the three main source waters, the southern, the northern (Labrador Sea or Iceland-Scotland/Denmark Strait overflow waters), and the Mediterranean. Therefore the high nutrient levels off Africa must be a result of either in situ nutrient regeneration or crossisopycnal mixing. It is also intriguing that the position of the extremum on the deeper surfaces is shifted northward from its position in the lower thermocline.

We consider it unlikely that the deep nutrient maximum is due to cross-isopycnal mixing down of the high-nutrient lower thermocline water. It is true that strong cross-isopycnal mixing due to salt fingering can be expected in the vicinity of the Mediterranean Outflow Water tongue. However, the map of $R_{\rho}$ (Figure 15) shows that the region of active salt fingering lies mostly to the north of the nutrient maximum. Moreover, the cross-isopycnal diffusivity coefficient due to salt fingering is a strong function of $\boldsymbol{R}_{\boldsymbol{\rho}}$. If most of the nutrients in the deep waters are mixed down rather than regenerated, we expect to see a pattern of nutrient distribution that is more akin to the salinity pattern. In particular, we should expect the nutrient maximum to shift further northward, where salt fingering activity is expected to be greatest.

We consider it more likely that regeneration is responsible for the nutrient maximum. Although regeneration is generally considered insignificant below the lower thermocline [Menzel and Ryther, 1968], it may be locally significant underneath a strong upwelling region such as the Saharan coast of Africa. Broecker et al. [1976] argue that the contrast in nutrient levels of the bottom waters between the eastern and the western basin of the Atlantic can be due to regeneration and silica dissolution from the bottom in the eastern basin. Silica dissolution can also occur from the sediments on the continental slope. Figure 10 shows that the silica maximum at the deep surfaces is strongly "coastally trapped." This argues for the possibility of silica dissolution from the sediments.

If regeneration is responsible for the deep nutrient maximum, the northward shift of the maximum compared with that at shallower surfaces can possibly be explained in two ways. First, the falling organic particulate matter from the surface ocean may be carried northward by a current within the intervening layer. Second, the region off Africa may be receiving oxgyen-rich and nutrient-free water from the south.

There is no strong indication that there exists the northward flowing eastern boundary current that the first hypothesis demands. Roemmich and Wunsch [1985] have found, using International Geophysical Year (IGY) hydrography, a fairly strong northward current (maximum velocity in excess of $0.5 \mathrm{~cm} / \mathrm{s}$ ) at $24^{\circ} \mathrm{N}$ off Africa between about 200 and $1400 \mathrm{~m}$ deep. It is strong enough to carry particulates over the required distance as they fall through the current, but with its shallow depth, one would expect to see the northward shift in the oxygen minimum already at the $\sigma_{2}=36.4$ surface. Moreover, it is doubtful that this current has any permanence and spatial continuity. Roemmich and Wunsch repeated the calculation using the section repeat of IGY in 1981 (the southern cross-Atlantic section of the Atlantis $I I$ cruise 109) to find a much weaker current in the eastern boundary. Stramma [1984] calculated the velocity field in the eastern Atlantic using mapped data and inverse methods and found that the waters in the depth range $1100-1300 \mathrm{~m}$ in the eastern Atlantic are stagnant. Hence we consider that the first mechanism is unlikely.

The second hypothesis, then, seems more attractive, especially since the deep western boundary current, which carries oxygen-rich, nutrient-poor waters from the north, seems to separate along the equator (see below). We must emphasize that the distribution of nutrients is a result of the subtle interplay of advection, mixing, and regeneration; fur- 
ther understanding of the mechanisms responsible for the deep nutrient maximum must come from a quantitative study of these relevant processes.

\section{Extension of the Deep Western Boundary Current}

Our data show that a part of the deep western boundary current seems to separate along the equator. As noted above, this feature is evident in Wust's [1935] core layer maps and is confirmed by the freon data. It is interesting to note that such a separation of the deep western boundary current has been observed in a relatively coarse $\left(\sim^{\circ}\right)$ resolution multilayer model of the ocean (F. O. Bryan, personal communication, 1985).

The problem of cross-equatorial boundary flow has been studied in connection with the east African jet in the atmosphere [Hart, 1977]. Anderson [1976] investigated beta plane shallow water models with varying degrees of simplification (linear viscous, nonlinear inviscid, etc.). His linear steady state solutions show no sign of the equatorial separation, since geostrophic contours (contours of equal potential vorticity) are blocked in the east where no flow condition applies. In nonlinear solutions [Anderson and Moore, 1979], separation occurs away from the equator. In time-dependent solutions [Anderson, 1981], however, Kelvin waves appear along the equator that carry signals away from the boundary current. This indicates that pulses of currents that travel down the western boundary as Kelvin waves may turn eastward upon reaching the equator. Thus fluctuations in the boundary current may be essential for the appearance of the boundary current water along the equator.

\section{CONCLUSION}

Our study of the nutrient distribution in the depth range 800-3300 $\mathrm{m}$ has covered two distinctly different strata of the ocean. The shallower stratum, which extends down to between 1200 and $1500 \mathrm{~m}$ is oxygen poor and nutrient rich and is poorly ventilated despite the fact that it outcrops extensively to the north. Below this is the North Atlantic Deep Water stratum, which is better ventilated than the layer above. Since both of these layers make contact with the atmosphere in the region of Ekman suction, ventilation due to the action of the wind stress curl alone as proposed by Luyten et al. [1983] is not possible. They, however, can still be ventilated through conversion of surface waters to waters of these densities by wintertime cooling. McCartney and Talley $[1982,1984]$ argue that wintertime cooling in the northern North Atlantic produces waters of densities discussed here. However, they argue, waters whose densities correspond to those of the shallower, less well ventilated layer get passed around in the cyclonic polar gyre, experiencing further cooling. Not until the water reaches the Labrador Sea and acquires the density of the Labrador Sea water $\left(\sigma_{2}=36.875 ;\right.$ Talley and McCartney [1982]) can it leave the polar gyre and enter the deep interior subtropical Atlantic. This seems to be the reason for the apparently paradoxical situation that the deeper layer is the better ventilated.

The deeper layer features the deep western boundary current, part of which separates along the equator. We tentatively postulate that baroclinic Kelvin waves along the western boundary may be responsible for the separation. The Mediterranean Outflow Water plays an active role in the water mass dynamics as a generator of cross-isopycnal mixing through salt fingering. This results in a net salt fallout from the Mediterranean Outflow Water tongue and accumulation of salt below the tongue, with a net downward density transport. The resultant cross-isopycnal velocity may be large enough to cause significant vorticity stretching.

Acknowledgments. The authors would like to thank in particular R. Williams and PACODF for work on the TTO data acquisition and processing, C. Wunsch for sharing the Atlantis II cruise 109 data, and W. Roether for making the Meteor data available. They also thank S. Hellerman for producing the distribution maps, M. Jackson for managing the data tapes, Bud Brown at MIT for graphics work, and R. Williams and the PACODF staff for technical assistance. We have also benefited from comments by F. Bryan, K. Bryan, R. X. Huang, S. Levitus, C. G. H. Rooth, J. R. Toggweiler, and anonymous reviewers. The illustrations group at GFDL/NOAA, under P. Tunison, drafted the property-property plots. This research was sponsored by ARL/NOAA grant NA83RAL00052, NSF grants OCE8117846 and OCE8110155, and DOE grant MM-19X-27405C.

\section{REFERENCES}

Anderson, D. L. T., The low-level jet as a western boundary current, Mon. Weather Rev., 104, 907-921, 1976.

Anderson, D. L. T., Cross-equatorial waves, with application to the low-level east African jet, Geophys. Astrophys. Fluid Dyn., 16, 267284, 1981 .

Anderson, D. L. T., and D. W. Moore, Cross-equatorial inertial jets with special relevance to very remote forcing of the Somali Current, Deep Sea Res., 26, 1-22, 1979.

Armi, L., and D. Haidvogel, Effects of variable and anisotropic diffusivities in a steady-state diffusion model, J. Phys. Oceanogr., 12, 785-794, 1982.

Broecker, W. S., Chemical signatures associated with the freshening of Northern Atlantic waters between 1972 and 1982, North Atlantic Deep Water Formation, NASA Conf. Publ. 2367, 13-17, 1985.

Broecker, W. S., and T. Takahashi, Hydrography of the central Atlantic, III, The North Atlantic deep-water complex, Deep Sea Res., 27, 591-613, 1980.

Broecker, W. S, T. Takahashi, and Y. H. Li, Hydrography of the central Atlantic, I, The two-degree discontinuity, Deep Sea Res., 23, 1083-1104, 1976.

Bryden, H. L., New polynomials for thermal expansion, adiabatic temperature gradient and potential temperature of sea water, Deep Sea Res., 20, 401-408, 1973.

Edmond, J. M., and G. C. Anderson, On the structure of the North Atlantic Deep Water, Deep Sea Res., 18, 127-133, 1971.

Fofonoff, N. P., Computation of potential temperature of seawater for an arbitrary reference pressure, Deep Sea Res., 24, 489-491, 1977.

Hall, M. M., and H. Bryden, Profiling the Gulf Stream with a current meter mooring, Geophys. Res. Lett., 12, 203-206, 1985.

Hart, J. E., On the theory of the east African low level jet stream, Pure Appl. Geophys., 115, 1263-1282, 1977.

Ivers, W. D., The deep circulation in the northern North Atlantic, with special reference to the Labrador Sea, Ph.D. thesis, Univ. of Calif, at San Diego, La Jolla, 1975.

Kawase, M., and J. L. Sarmiento, Nutrients in the Atlantic thermocline, J. Geophys. Res., 90, 8961-8979, 1985.

Leetmaa, A., P. Niiler, and H. Stommel, Does the Sverdrup relation account for the Mid-Atlantic circulation?, J. Mar. Res., 35, 1-10, 1977.

Levitus, S., Climatological atlas of the World Ocean, NOAA Prof. Pap. 13, 1982.

Luyten, J. L., J. Pedlosky, and H. Stommel, The ventilated thermocline, J. Phys. Oceanogr., 13, 292-309, 1983.

McCartney, M. S., and L. D. Talley, The Subpolar Mode Water of the North Atlantic Ocean, J. Phys. Oceanogr., 12, 1169-1188, 1982.

McCartney, M. S., and L. D. Talley, Warm-to-cold water conversion in the northern North Atlantic Ocean, J. Phys. Oceanogr., 14, 922$935,1984$.

McDougall, T. J., The relative roles of diapycnal and isopycnal mixing on subsurface water mass conversion, J. Phys. Oceanogr. $14,1577-1589,1984$.

Menzel, D. W., and J. H. Ryther, Organic carbon and the oxygen minimum in the South Atlantic, Deep Sea Res., 15, 327-337, 1968.

Nof, D., On geostrophic adjustment in sea straits and wide estuaries: Theory and laboratory experiments, II, Two layer system, J. Phys. Oceanogr., 8, 861-872, 1978. 
Philander, S. G. H., and J. H. Yoon, Eastern boundary currents and coastal upwelling, J. Phys. Oceanogr., 12, 862-879, 1982

Pingree, R. D., Mixing in the deep stratified ocean, Deep Sea Res., 19, 549-561, 1972

Pingree, R. D., and G. K. Morrison, The relationship between stability and source waters for a section in the northeast Atlantic, $J$. Phys. Oceanogr, 3, 280-285, 1973.

Reid, J. L., On the middepth circulation and salinity field in the North Atlantic Ocean, J. Geophys. Res., 83, 5063-5067, 1978.

Reid, J. L., On the contribution of the Mediterranean Sea outflow to the Norwegian-Greenland Sea, Deep Sea Res., 26, 1199-1223, 1979.

Reid, J. L., On the mid-depth circulation of the world ocean, in Evolution of Physical Oceanography: Scientific Surveys in Honor of Henry Stommel, edited by B. Warren and C. Wunsch, pp. 70-111, MIT Press, Cambridge, Mass., 1981.

Reid, J. L., and R. J. Lynn, On the influence of Norwegian-Greenland and Weddell seas upon the bottom waters of the Indian and Pacific oceans, Deep Sea Res., 18, 1063-1088, 1971.

Richardson, P. L., Average velocity and transport of the Gulf Stream near 55 W, J. Mar. Res., 43, 83-111, 1985.

Richardson, P. L., and K. Mooney, The Mediterranean outflow-A simple advection-diffusion model, $J$. Phys. Oceanogr., 5, 476-482, 1975.

Roemmich, D., and C. Wunsch, Two trans-Atlantic sections: Meridional circulation and heat flux in the subtropical North Atlantic Ocean, Deep Sea Res., 32, 619-664, 1985.

Sarmiento, J. L., C. G. H. Rooth, and W. Roether, The North Atlantic tritium distribution in 1972, J. Geophys. Res., 87, 8047-8056, 1982a.

Sarmiento, J. L., J. Willebrand, and S. Hellerman, Objective analysis of tritium observations in the Atlantic Ocean during 1971-74, Tech. Rep. 1, Ocean Tracers Lab., Dep. of Geol. and Geophys. Sci., Princeton Univ., Princeton, N. J., $1982 b$.

Saunders, P., Circulation in the eastern North Atlantic, J. Mar. Res., 40(Suppl.), 641-657, 1982.

Schmitt, R. W., Growth rate of super-critical salt fingers, Deep Sea Res., 26A, 23-40, 1979.

Schmitt, R. W., Form of the temperature-salinity relationship in the central water: Evıdence for double-diffusive mixing, J. Phys. Oceanogr., 11, 1015-1026, 1981.

Stommel, H., Determination of water mass properties of water pumped down from the Ekman layer to the geostrophic flow below, Proc. Nat. Acad. Sci. USA, 76, 3051-3055, 1979.
Stramma, L., Geostrophic transport in the warm water sphere of the eastern subtropical North Atlantic, J. Mar. Res., 42, 537-558, 1984.

Swift, J. H., A recent $\theta$-S shift in the deep waters of the northern North Atlantic, in Climate Processes and Climate Sensitivity, Geophys. Monogr. 29, edited by J. Hansen, and T. Takahashi, pp. 39-47, AGU, Washington, D. C., 1984.

Tait, R. I., and M. R. Howe, Some observations of thermohaline stratification in the deep ocean, Deep Sea Res., 15, 275-280, 1968.

Talley, L. D., and M. S. McCartney, Distribution and circulation of Labrador Sea water, J. Phys. Oceanogr., I2, 1189-1205, 1982.

Turner, J. S., Salt fingers across a density interface, Deep Sea Res., 14, 599-611, 1967.

UNESCO, Tenth report of the joint panel on oceanographic tables and standards, Tech. Pap. Mar. Sci. 36, UNESCO, Paris, 1981.

Weiss, R. F., J. L. Bullister, R. H. Gammon, and M. J. Warner, Atmospheric chlorofluoromethanes in the deep equatorial Atlantic, Nature, 314, 608-610, 1985.

Worthington, L. V., On the North Atlantic circulation, Johns Hopkins Oceanogr. Stud. 6, 110 pp., Johns Hopkins University Press, Baltimore, Md., 1976.

Worthington, L. V., and W. R. Wright, North Atlantic Ocean atlas of potential temperature and salinity in the deep water including temperature, salinity and oxygen profiles from the Erika Dan cruise of 1962, Woods Hole Oceanogr. Inst. Atlas Ser., 2, 24 pp., 1970.

Wunsch, C., and B. Grant, Towards the general circulation of the North Atlantic Ocean, Progr. Oceanogr., 11, 1-59, 1982.

Wust, G., The Stratosphere of the Atlantic Ocean, edited by W. J. Emery, 112 pp., translated from German by the Al-Ahram Center for Scientific Translations, Amerind Publishing, New Delhi, 1978.

Zenk, W., On the temperature and salinity structure of the Mediterranean Water in the northeast Atlantic, Deep Sea Res., 17, 627631,1970 .

M. Kawase, Department of Earth, Atmospheric and Planetary Sciences, Massachusetts Institute of Technology, Cambridge, MA 02139.

J. L. Sarmiento, Geophysical Fluid Dynamics Program, Princeton University, P. O. Box 308, Princeton, NJ 08542.

(Received November 6, 1985; accepted January 10, 1986.) 